\title{
A simple model for interannual sandbar behavior
}

\author{
N. G. Plant, ${ }^{1}$ R. A. Holman, and M. H. Freilich \\ College of Oceanic and Atmospheric Sciences, Oregon State University, Corvallis \\ W. A. Birkemeier \\ U.S. Army Corps of Engineers Field Research Facility, Kitty Hawk, North Carolina
}

\begin{abstract}
Time and length scales of beach variability have been quantified using 16 years of beach surveys sampled at the Army Corps of Engineers' Field Research Facility, located on the U.S. Atlantic coast. Between $50 \%$ and $90 \%$ of the bathymetric variability at this site was explained by alongshore-uniform response over the approximately $1 \mathrm{~km}$ alongshore span of the surveys. Although the incident wave height variance was dominated by frequencies at or higher than 1 cycle/yr, more than $80 \%$ of the bathymetric variance at all cross-shore locations was explained by frequencies $<1$ cycle/yr. Interannual cycles consisting of sandbar formation, migration, and decay contributed to the lowfrequency variability. The observed behavior can be explained by a simple, heuristic model. The model assumes that bars migrate toward a wave height dependent equilibrium position. This position was shown to coincide with the wave "breakpoint." Additionally, the rate of bar response is taken to be variable and was empirically determined to be proportional to the wave height cubed. The net effect of a variable response rate is to shift the expected long-term mean sandbar position offshore, toward the equilibrium position associated with the largest waves. The model explained up to $80 \%$ of the observed bar position time series variance and up to $70 \%$ of the variance of bar crest velocity time series, which were extracted from three different sandbars. Characteristic bar response times (related to the inverse of the response rate) were found to be long relative to the characteristic timescale of the forcing (1 year in our case). As a result, transient response (i.e., bar position far from equilibrium) tended to persist for many cycles of the forcing. Transient bar behavior appears in the observations when bars formed near the shoreline or when outer bars decayed and inner bars faced a changed wave climate. While the present model is able to explain the evolution of these transients, it does not contain a mechanism for their introduction.
\end{abstract}

\section{Introduction}

On most natural beaches, unconsolidated sediments are arranged by wave action into a set of patterns, known collectively as the beach morphology. Most common are sandbars, which, typically, are shore parallel to rhythmic or irregular shoals. Sandbars are often found at locations having surf zones, whose width is modulated by variations in the incident wave climate. Changes in sandbar morphologies in association with changing wave conditions are often striking (Figure 1) and have been extensively documented [e.g., Sonu, 1969, 1973; Short, 1975; Wright and Short, 1984; Lippmann and Holman, 1990]. A primary goal of nearshore processes research has been to develop a set of predictive models for the generation and evolution of sandbar morphology under wave forcing. However, a prerequisite to this work is the development of a simplified description of the morphology in terms of a small number of parameters.

One approach to the quantification of beach morphology has been the identification of a set of morphologic states, in

\footnotetext{
${ }^{1}$ Now at Civil Technology and Management, University of Twente, Enschede, Netherlands.

Copyright 1999 by the American Geophysical Union.

Paper number $1999 \mathrm{JC} 900112$. 0148-0227/99/1999JC900112\$09.00
}

analogy to taxonomies that have been developed in ecosystem studies. A simple but well-known example of this morphologic state parameterization is the summer-winter (or bar-berm) model. This approach is based on observations that the shape of many beaches tends to change from an unbarred (summer or berm) profile to a barred (winter) profile when low-energy, summer wave conditions give way to high-energy conditions of winter [Shepard, 1948; Komar, 1974]. Another commonly referenced example is the set of six morphological states proposed by Wright and Short [1984] to classify variations (based on visual observations) of beach morphology, both temporally at any location and spatially throughout the world.

Alternatively, parameterizations of beach morphology may be based on surveyed bathymetry. For example, Winant et al. [1975] utilized empirical orthogonal functions as objective descriptors of bathymetric variability. It is also common to extract simple measures from bathymetry, for example, the bar crest location or depth, to represent the variability of a sandbar [Birkemeier, 1985; Lippmann and Holman, 1990; Ruessink and Kroon, 1994].

It is often assumed that a particular set of incident wave conditions is associated with a stable equilibrium state of the beach [Wright et al., 1985]. That is, if wave conditions were steady, a beach would asymptotically approach a single state, independent of the initial state. A well-known application of the equilibrium assumption is the "breakpoint" hypothesis, 


\section{October 1995}

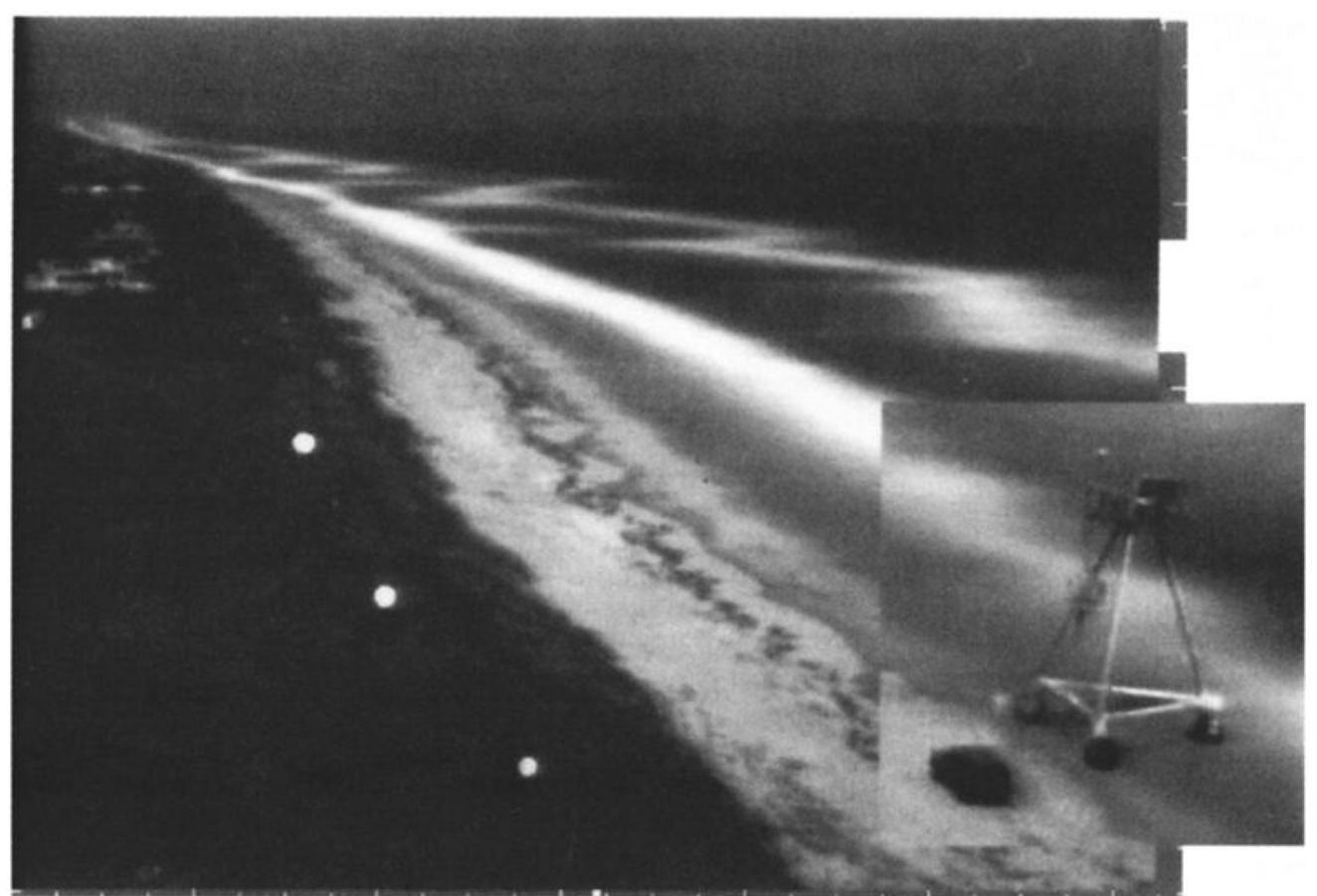

17 February 1996

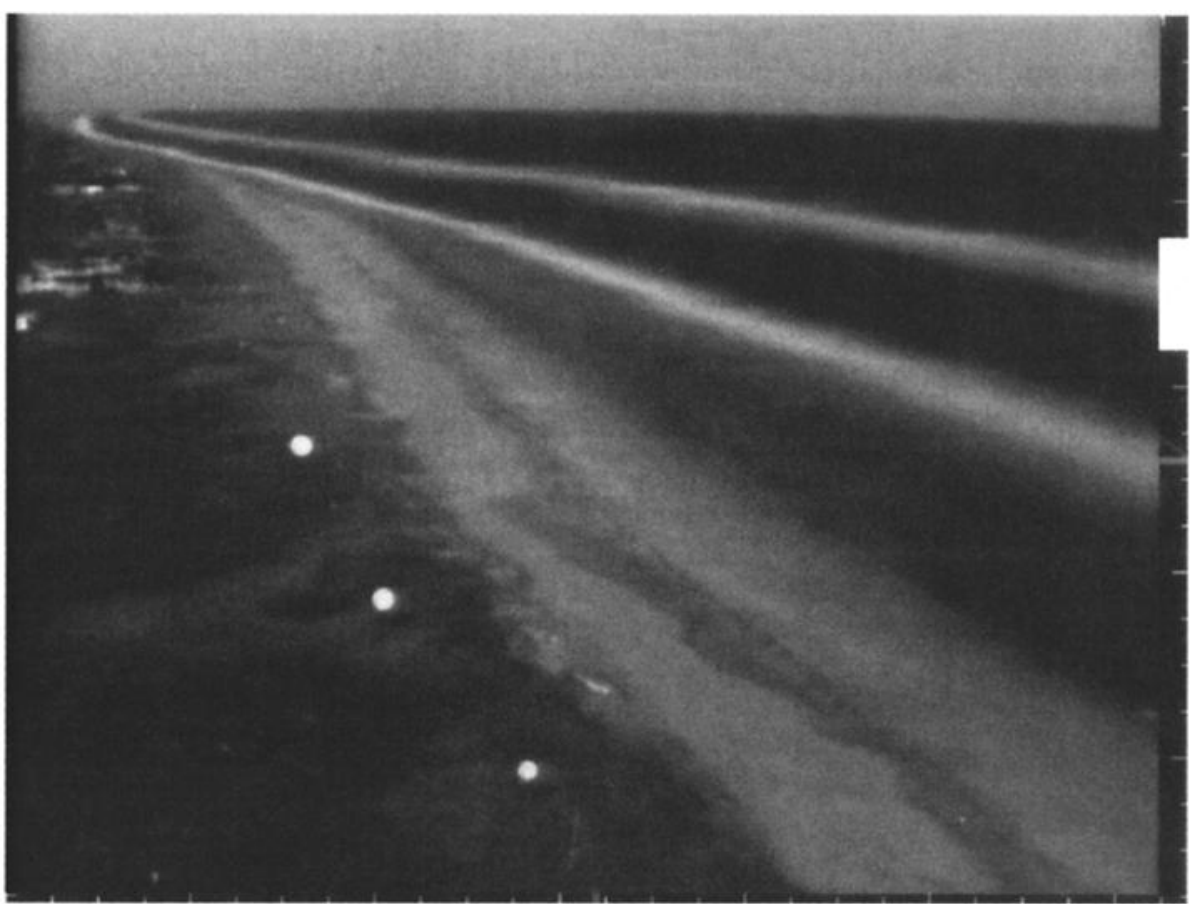

Figure 1. Time exposure images from Duck, North Carolina (Field Research Facility (FRF)), showing (a) irregular and (b) shore-parallel sandbars. Time exposure images (averaged over a 10-minute period) show stable foam patterns produced by waves, which break over sandbars and near the shoreline. The coastal research amphibious buggy (CRAB), used to conduct bathymetric surveys at this site, is shown in the inset next to a full sized vehicle (Chevrolet Suburban).

which postulates that sandbars form at the location of initial wave breaking [Dean, 1973; Dally, 1987] or that existing bars would migrate toward this location [Sallenger et al., 1985; Sallenger and Howd, 1989]. Some studies found that changes in bar crest position were correlated with changes in wave con- ditions [Wright et al., 1985; Lippmann and Holman, 1990], suggesting that bathymetric evolution was dominated by the same weekly to seasonal timescales characteristic of wave-forcing variability (e.g., Figure 2 ).

In the variable wave climate observed in nature, beaches 


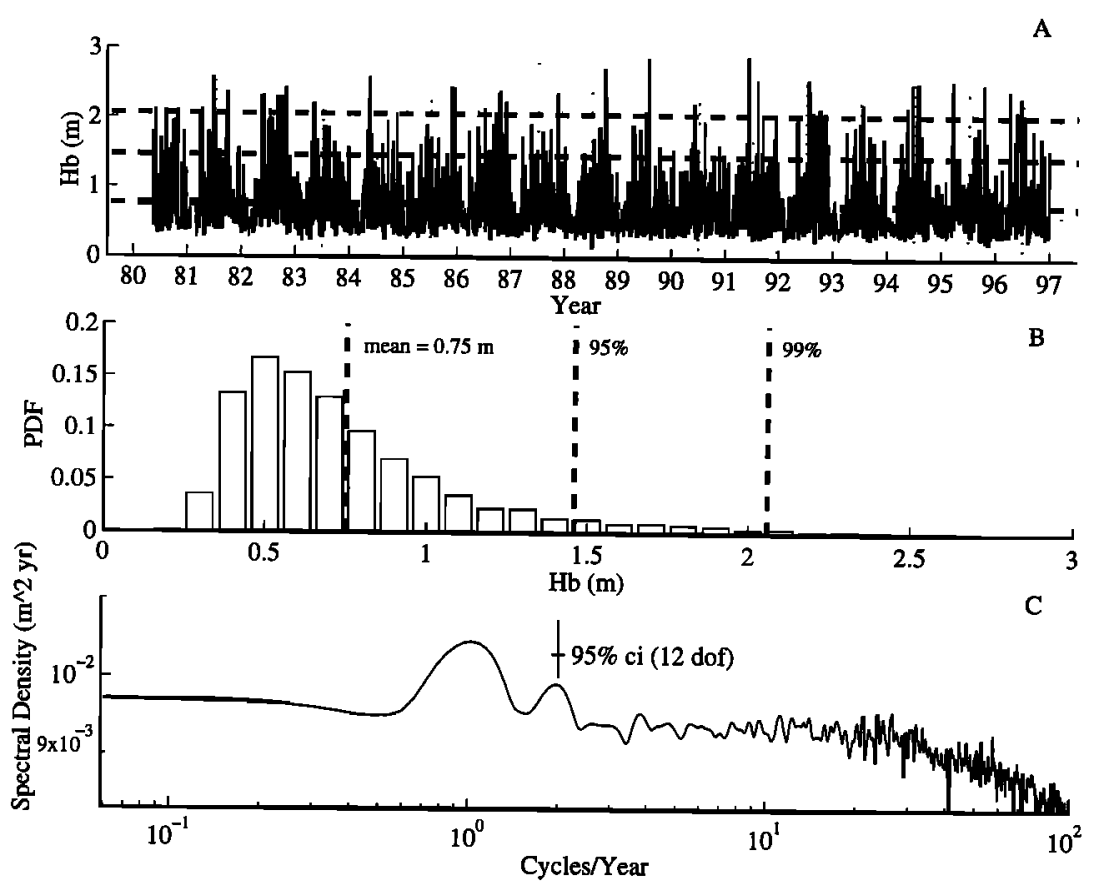

Figure 2. (a) Time series of daily averaged rms wave heights measured over a 16-year period at the FRF site. The wave height has been transformed to the predicted value at breaking. The dashed lines indicate (from the top) 99 and 95 percentiles and the mean. These levels are marked on the (b) probability density function (pdf). The (c) spectrum indicates significant energy peaks at annual and semiannual frequencies.

may continually evolve toward a time-varying equilibrium state defined by the fluctuating forcing. Potentially, the instantaneous morphology may not be well correlated to the instantaneous wave forcing. Recently, dominant interannual sandbar variability has been observed [Birkemeier, 1985; Lippmann et al., 1993; Ruessink and Kroon, 1994], consisting of net seaward migration of sandbars over periods exceeding a decade. This variability was not correlated with observed variations in the wave conditions (in fact, wave climate shows only minor interannual variability [Lippmann et al., 1993]).

Ruessink and Kroon [1994] (hereinafter referred to as RK94) provide a good example of long-timescale variability, based on an analysis of 30 years of annual beach profile surveys, collected over a $100-\mathrm{km}$-long coastline in Netherlands. They describe interannual sandbar cycles in these data consisting of bar generation near the shoreline, net seaward propagation, and final decay when sandbars reached the outer extent of the surf zone. Surprisingly, seaward sandbar migration took place without significant net sediment loss or gain from the system as a whole. Although the pattern of seaward migration was uniform over many kilometers of the coastline, Wijnberg and Terwindt [1995] showed that the characteristic duration of interannual sandbar cycles could change dramatically across sharp geographic boundaries. For example, the duration of sandbar cycles changed from about 15 to 4 years on opposite sides of a jetty despite similar forcing and geologic conditions.

Long-term, seaward bar migration has also been observed on the U.S. east coast at the Army Corps of Engineers Field Research Facility (FRF), located at Duck, North Carolina. Using 3 years (1981-1983) of the survey data at this site, Birkemeier [1985] mapped the end of one interannual bar cycle (outer bar decay), followed by offshore migration of an inner bar, and generation of a new inner bar near the shoreline. The bar response was coherent over the $1-\mathrm{km}$ alongshore extent of the surveys. Using video time exposure images (Figure 1), Lippmann et al. [1993] documented the completion of a second cycle in 1989, suggesting approximately 7-year periodicity (1982 to 1989). Both Birkemeier [1985] and Lippmann et al. [1993] observed that the decay of an outer bar was followed within 1 year by rapid offshore migration of an existing inner bar and generation of a new sandbar near the shoreline. These transitions occurred synchronously with large storm waves, where the wave height was several times the annual average. However, there were many apparently similar storms that did not precipitate new sandbar cycles.

The primary objective of the present study is to determine if a simple equilibrium beach response model can yield accurate predictions of interannual bar migration when forced with realistic, weekly to seasonally varying wave conditions. In the next section (section 2) a simple, heuristic, equilibrium model for cross-shore bar migration is developed and used to establish quantitative predictions that can be compared with observed sandbar response. In section 3 an extensive data set of more than 400 bathymetric surveys, collected over a 16-year period at the FRF, is introduced and described statistically. Using an approach similar to that of RK94, time series of sandbar properties needed to test the equilibrium model are extracted from the bathymetric data. In section 4 the migration of sandbar crests in response to variations in incident wave height is compared to predictions based on the equilibrium model. Discussion and conclusions follow in sections 5 and 6 , respectively.

\section{Equilibrium Theory}

Beach morphology reaches equilibrium when time-averaged sediment transport gradients vanish everywhere. If we consider alongshore-uniform models, the cross-shore sediment trans- 
port must vanish everywhere. Process-based equilibrium models were derived by Bowen [1980] and Bailard and Inman [1981]. In these models, sediment transport was considered to be driven by several simple processes, including the tendency for offshore (downslope) transport driven by "stirring" due to oscillatory currents and the tendency for net onshore transport driven by a skewed velocity distribution or a mean current. At equilibrium the rate of sediment transport reduces to zero (if transport also vanishes at either the offshore or onshore boundary) and the resulting equilibrium profile can be found from a balance of the above terms. These process-based equilibrium models predict a monotonic cross-shore profile (e.g., $h \sim x^{2 / 3}$, where $h$ is depth and $x$ is distance from the shoreline).

It seems reasonable that more complex morphologic patterns, such as shore-parallel and crescentic sandbars, may also represent equilibrium morphologies. In these cases a perturbation to the underlying concave profile could be provided by net transport driven by low-frequency wave modes [Bowen, 1980; Bowen and Huntley, 1984]. Holman and Bowen [1982] showed that realistic equilibrium (barred) bathymetries over a two-dimensional (2-D) horizontal domain could be produced in the presence of forcing from sets of edge wave modes.

Precise calculations of equilibrium morphologies require a complete description of the forcing and sediment transport at all locations, a daunting task. However, assuming that sandbars do approach an equilibrium state and that bar morphology is adequately described by only the cross-shore position of the bar crest (bar shape is assumed unchanging), it is possible to construct an idealized, equilibrium model to predict bar migration. One of the simplest such models constrains a bar to migrate toward a (time dependent) equilibrium position at a rate determined by both a (time dependent) response time and the instantaneous distance of the bar from the equilibrium position:

$$
\frac{d X_{c}}{d t}=-\alpha(t)\left[X_{c}(t)-X_{\mathrm{eq}}(t)\right]
$$

where $X_{c}$ represents the cross-shore position of an alongshoreuniform sandbar, $\alpha^{-1}$ is the response time $(\alpha>0)$, and $X_{\text {eq }}$ is the equilibrium bar crest position. It will be assumed that the response time and equilibrium position depend on the timevarying wave height. Although Wright et al. [1985] proposed a similar model to predict changes between a set of three beach states (reflective, intermediate, and dissipative), the full range of bar response predicted by this sort of model has not previously been described or compared quantitatively to observations.

A solution to (1) can be obtained for the situation of a constant response time and periodic forcing of the equilibrium position. Let

$$
\begin{gathered}
\alpha(t)=\alpha_{0} \\
X_{\text {eq }}(t)=A_{0} \sin (\omega t) .
\end{gathered}
$$

These conditions represent, for example, a seasonal variation of the wave height (i.e., $\omega=2 \pi \mathrm{yr}^{-1}$ ) that drives an equilibrium bar position toward the breakpoint, which varies between $x=A_{0}$ and $x=-A_{0}$. The solution to (1) is given by

$X_{c}(t)=\left(X_{0}+X_{1}\right) \exp \left(-\alpha_{0} t\right)+A_{0}\left(\frac{\alpha_{0}}{\sqrt{\alpha^{2}+\omega^{2}}}\right) \sin (\omega t-\phi)$, where

$$
\phi=\tan ^{-1}\left(\omega / \alpha_{0}\right)
$$

Equation (2c) shows that the introduction of a time-varying forcing and a finite response time in (1) causes two changes from our original equilibrium thinking (which was based on constant forcing). The first (exponential) term on the righthand side of (2c) represents a transient response from an initial position, $X_{0}$, which decays over a timescale of $1 / \alpha_{0}$. The second (sinusoidal) term in (2c) shows that, as a result of the finite response time, the periodic response is phase shifted relative to the forcing by $\phi$ and has an amplitude, which is damped in proportion to $\alpha_{0}\left(\alpha_{0}^{2}+\omega^{2}\right)^{-1 / 2} .\left(X_{1}=\alpha_{0} \omega A_{0} / \alpha_{0}^{2}+\omega^{2}\right.$ is simply a correction for the nonzero contribution of the second term in (2c) at $t=0$.)

It seems likely that $\alpha$ is not constant in nature but, instead, varies as some function of the wave forcing. Sediment transport, whose gradients drive sandbar migration, is usually assumed to depend on near-bottom velocities (hence wave height) raised to some power $p$. For example, Bagnold [1963] derived values of $p=3$ or 4, while Komar and Inman [1970] presented an example of $p=2.5$ for alongshore sediment transport. Assuming that $\alpha$ should scale with transport, we model the rate dependence as

$$
\alpha(t)=a_{1} H(t)^{p},
$$

where $H$ is the wave height. In addition, we will assume that the equilibrium position of the bar crest is also a function of wave height:

$$
X_{\mathrm{eq}}(t)=a_{2} H(t) .
$$

This formulation (3b) is most readily viewed as a breakpoint hypothesis if $a_{2}$ relates the wave height at breaking to the cross-shore location of the breakpoint. However, it makes no ad hoc assumptions about the magnitude of $a_{2}$ and so could also be consistent with any other process that scales with wave height.

We introduce some nondimensional scales, which aid the interpretation of the model parameters $a_{1}$ and $a_{2}$ :

$$
\begin{gathered}
X^{*}=X_{c} / X_{\mathrm{sz}} \\
H^{*}=H / H_{\max } \\
t^{*}=t \omega .
\end{gathered}
$$

Bar position has been scaled by the maximum surf zone width $\left(X_{\mathrm{sz}}\right)$ and wave height has been scaled by the maximum wave height $\left(H_{\max }\right)$, so that the equilibrium bar position corresponds to the surf zone width if $a_{2}^{*}=1$, where

$$
a_{2}^{*}=a_{2} H_{\max } / X_{\mathrm{sz}} \text {. }
$$

Time has been scaled by the characteristic frequency of the forcing $(\omega)$. If $a_{1}^{*}=1$, where

$$
a_{1}^{*}=a_{1} H_{\max }^{p} / \omega
$$

the characteristic timescale of bar migration is equivalent to that of the forcing (that is, a bar can traverse the width of the surf zone and return to its original position in one cycle of the forcing).

Substitution of these scales (4a)-(4e) and (3a) and (3b) into (1) yields 

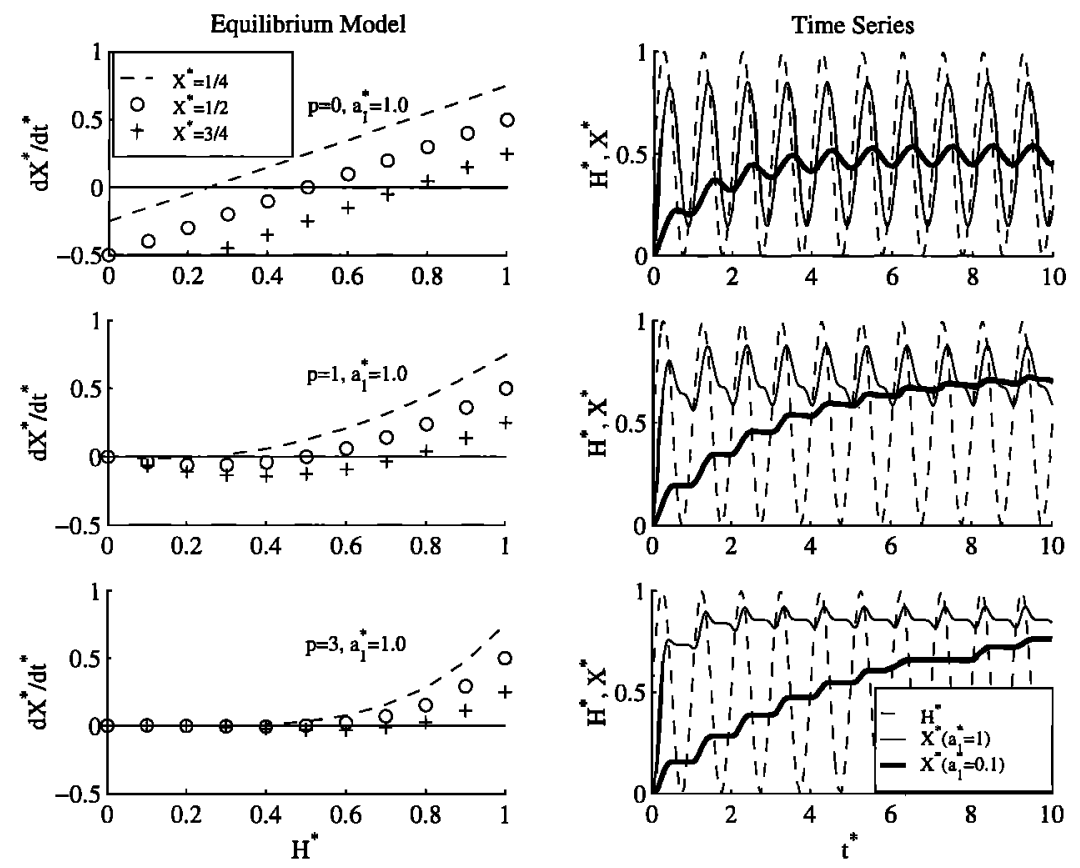

Figure 3. Equilibrium model predictions. (left) Predicted migration rate $\left(d X^{*} / d t^{*}\right)$ as a function of wave height $H^{*}$, with different values of $p$ and $a_{1}^{*}=1$. The bar crest position was varied in order to generate a family of curves. (right) Predictions of bar position, driven by sinusoidal variations in the wave height. Calculations were made with $a_{1}^{*}=1.0$ and $a_{1}^{*}=0.1$, illustrating the differences in phase shift, damping, and persistence of the transient response.

$$
\frac{d X^{*}}{d t^{*}}=-a_{1}^{*}\left(H^{*}\right)^{p}\left(X^{*}-a_{2}^{*} H^{*}\right)
$$

The behavior of the model (4f) is demonstrated in Figure 3. Figure 3 (left) show the predicted bar crest velocity as a function of nondimensional wave height, with the nondimensional bar position fixed at three different values. For all cases where $p>0$, the response becomes insensitive to changes in the wave height or bar position for low wave heights. Clearly, for large $p$, offshore migration dominates bar response.

Figure 3 (right) shows time series of the response for $a_{1}^{*}=$ 1 (response time comparable to the timescale of the forcing) and $a_{1}^{*}=0.1$ (long response time). Wave height variations were periodic: $H^{*}=0.5\left[1+\sin \left(t^{*} / 2 \pi\right)\right]$ and the bar was initialized at the "shoreline" $\left(X^{*}=0\right)$. Transient, offshore migration persisted over a timescale of $a_{1}^{*-1}$. Following a period of transient response, the bar position oscillated about a long-term mean position (located at $\overline{X^{*}}=1-[2(p+1)]^{-1}$ ), which increased with increasing $p$. Thus, if sandbar response times are long relative to the timescale of the forcing, net seaward migration may persist as a transient response, especially for larger values of $p$.

\section{Field Data Description}

\subsection{Data Collection and Processing}

Since 1981, both biweekly and monthly beach surveys have been performed at the FRF using the coastal research amphibious buggy (CRAB) (Figure 1). The elevations have been referenced to the National Geodetic Vertical Datum (NGVD29), which lies about $0.25 \mathrm{~m}$ below the mean water level at the FRF site. Over a smooth bottom the vertical accuracy of each elevation observation was about $10 \mathrm{~cm}$ [Birkemeier and Mason,
1984]. This error estimate does not account for unresolved bed forms, such as megaripples $(O(1 \mathrm{~m})$ wavelengths and $O(10$ cm) amplitudes, e.g., Gallagher et al. [1996]).

The surveys typically extended from the back beach to about $8-\mathrm{m}$ water depth (about $1 \mathrm{~km}$ offshore) and spanned roughly 1 $\mathrm{km}$ alongshore, centered about the FRF pier (Figure $4 \mathrm{a}$ ). The cross-shore sample interval varied from about 50 to $1 \mathrm{~m}$ as survey technology improved over the 16-year period. Not all observations were independent, since the CRAB's footprint spanned $10 \mathrm{~m}$.

The alongshore sample spacing ranged from 25 to $100 \mathrm{~m}$. Twenty-six transects were surveyed approximately monthly, while biweekly surveys sampled 4 of the 26 cross-shore transects, two at the south end $(y=-92,0 \mathrm{~m})$ and two at the north end ( $y=1006,1096 \mathrm{~m}$ ) of the study area. A total of 449 different surveys from January 1981 to August 1996 have been analyzed.

The raw survey data were interpolated to a grid (Figures $4 a-4 c)$ with a cross-shore spacing of $5 \mathrm{~m}$ and an alongshore spacing that matched the locations of the regularly occupied cross-shore transects. An objective (suboptimal) interpolation method [Ooyama, 1987] was used, which is described in Appendix A. The interpolation scheme imposed an adjustable spatial filter that was tuned to damp potentially unresolved cross-shore and alongshore length scales (cross-shore scales $<25 \mathrm{~m}$ and alongshore scales $<100 \mathrm{~m}$ ). The interpolation scheme also yielded an interpolation error estimate, which was the expected error between the interpolated surface and the spatially filtered version of the true surface. Interpolation errors resulted from measurement error, unresolved morphology (e.g., megaripples and beach cusps), and the mismatch between the true spatial covariance structure and an assumed Gaussian covariance model. Only interpolated values with an 


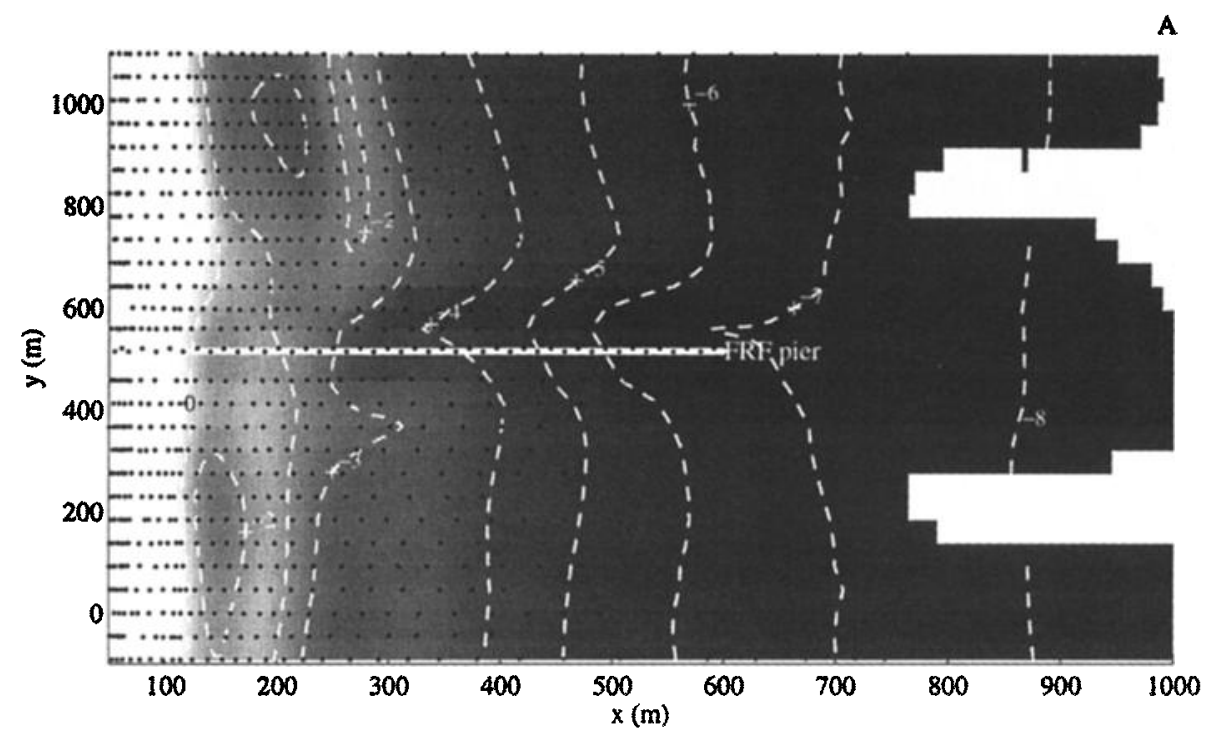

B
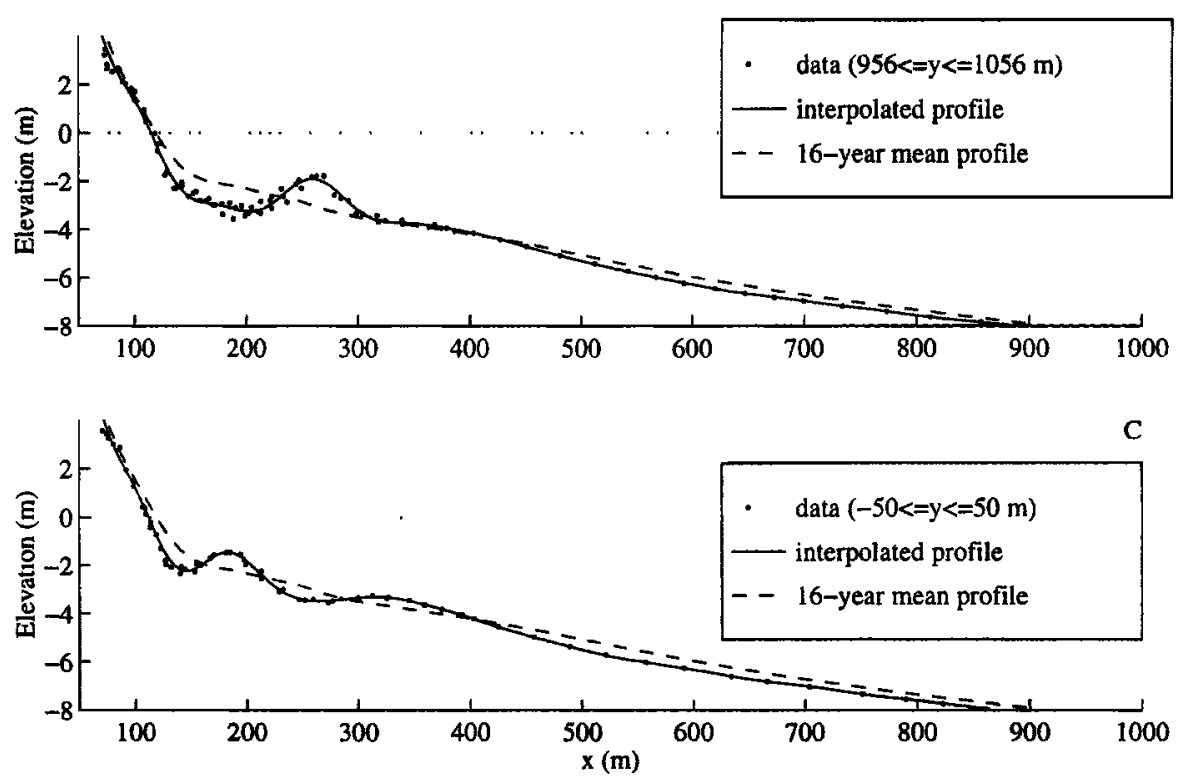

Figure 4. (a) Contour map and (b and c) profiles of surveyed bathymetry on December 19, 1985. Contour interval is $1 \mathrm{~m}$, and the shading maps elevations between $-8 \mathrm{~m}$ (black) and $0 \mathrm{~m}$ (white). Dots indicate locations of bathymetric observations. Note the differences in bar positions north and south of the pier.

estimated rms interpolation error less than $20 \mathrm{~cm}$ were included in the subsequent analyses.

\subsection{Spatial Patterns of Variability}

The use of the single morphologic parameter, $X_{c}$, to describe profile variability is only strictly valid for an alongshoreuniform sandbar having a fixed cross-shore spatial structure. We tested this assumption by estimating the fraction of the total temporal variance that was alongshore uniform. First, the three-dimensional bathymetric data, $Z(x, y, t)$, were decomposed into a time-mean bathymetry $(\bar{Z})$ and deviations from the mean $\left(Z^{\prime}\right)$,

$$
Z(x, y, t)=Z^{\prime}(x, y, t)+\bar{Z}(x, y) .
$$

Figure 5a shows the 16-year mean beach elevation at each grid location. The bathymetry has a pronounced shore-perpendic- ular trough with a high standard deviation (Figure 5b) beneath the pier. This feature corresponds to a known bathymetric anomaly associated with wave interference and scour around pier pilings. Because beach behavior in this region is not representative of open beach dynamics, the central region of the field area (within $200 \mathrm{~m}$ of the pier) was excluded from the analyses to follow. The remaining north region was bounded by transects along $y=776,1096 \mathrm{~m}$ and the south region was bounded by $y=-92,228 \mathrm{~m}$.

Figure 6a shows profiles that have been both time- and alongshore-averaged within the north and south regions (300-m averages) and across the full 1-km alongshore extent, excluding the region near the pier.

$$
\bar{Z}_{Y}(x)=\sum_{y=Y_{1}}^{Y_{2}} \bar{Z}(x, y) / N_{Y},
$$



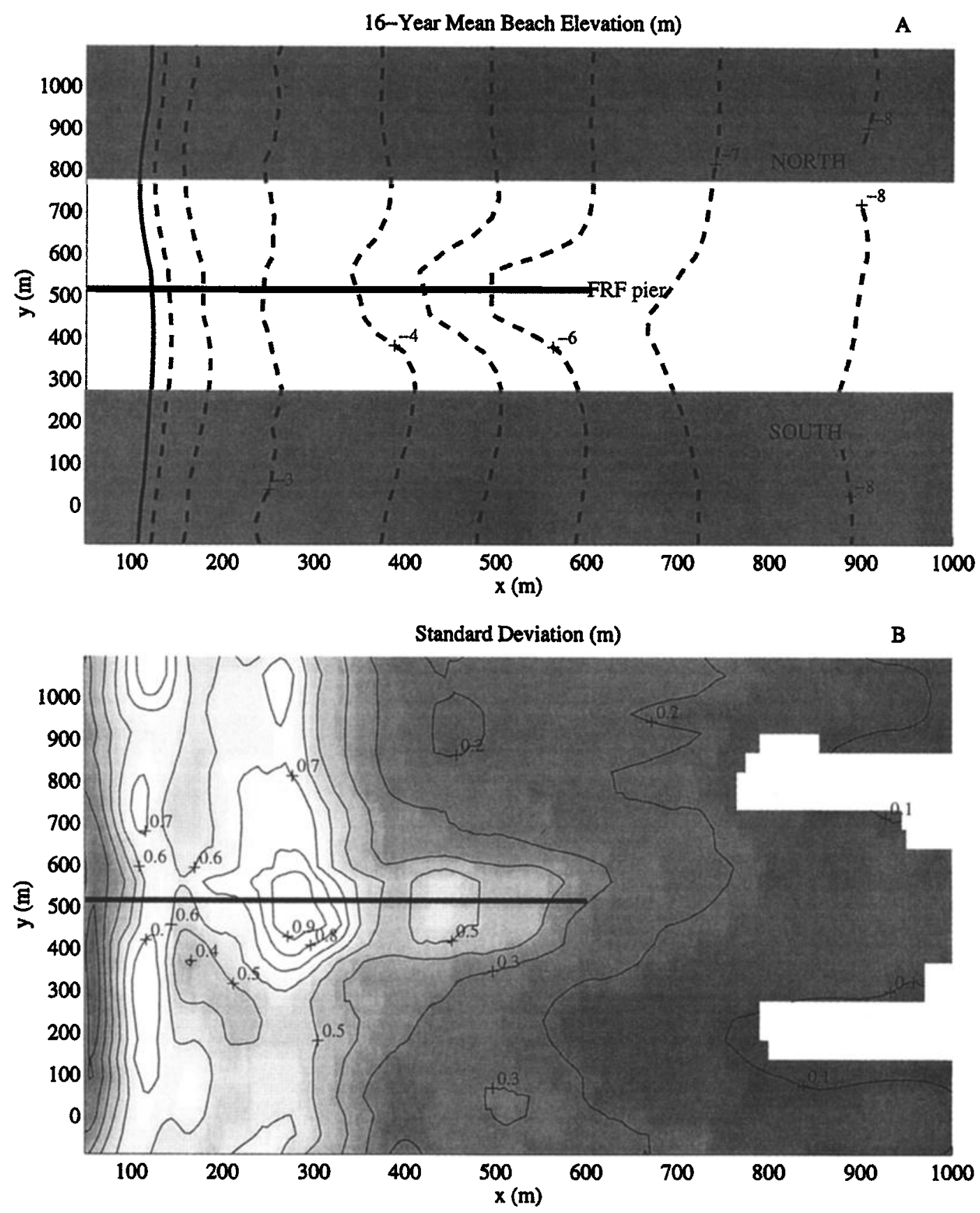

Figure 5. (a) Sixteen-year mean and (b) standard deviation of interpolated elevations. The contour intervals are $1 \mathrm{~m}$ for the mean and $0.1 \mathrm{~m}$ for the standard deviation. Interpolated profiles within the shaded regions (Figure 5a) were included in our analysis. Contours are not plotted across regions where interpolation errors of at least half of the observations exceeded $0.2 \mathrm{~m}$. The gray-scale shading in Figure $5 \mathrm{~b}$ is proportional to the standard deviation $(0=$ black, $1=$ white $)$.

where $N_{Y}$ are the number of cross-shore profiles within each region $Y$. Differences between these mean profiles were small (the profiles overlie one another), relative to the magnitudes of temporal deviations. The shape of the mean profiles consisted of two nearly planar sections intersecting at a mean depth of about $2 \mathrm{~m}$. The slope of the landward section was about $1 / 25$, and the slope of the seaward section was about $1 / 100$. It is, perhaps, surprising that the mean profile was not a more concave-up function (in the offshore region), such as the expected $x^{2 / 3}$ profile discussed previously.
Standard deviation profiles $\left(S_{Y}\right)$ were estimated as the rootmean-square deviation, averaged in both time and alongshore,

$$
S_{Y}^{2}(x)=\sum_{y=Y_{1}}^{Y_{2}} \sum_{j=1}^{N_{t}}\left[Z^{\prime}\left(x, y, t_{j}\right)\right]^{2} /\left(N_{Y} N_{t}\right)
$$

The shapes of these profiles in the north and south regions were similar, and hence they were similar to the data set average (Figure 6b). Variance was low at the onshore limit of the surveys (in the dunes and back beach), and it was high 

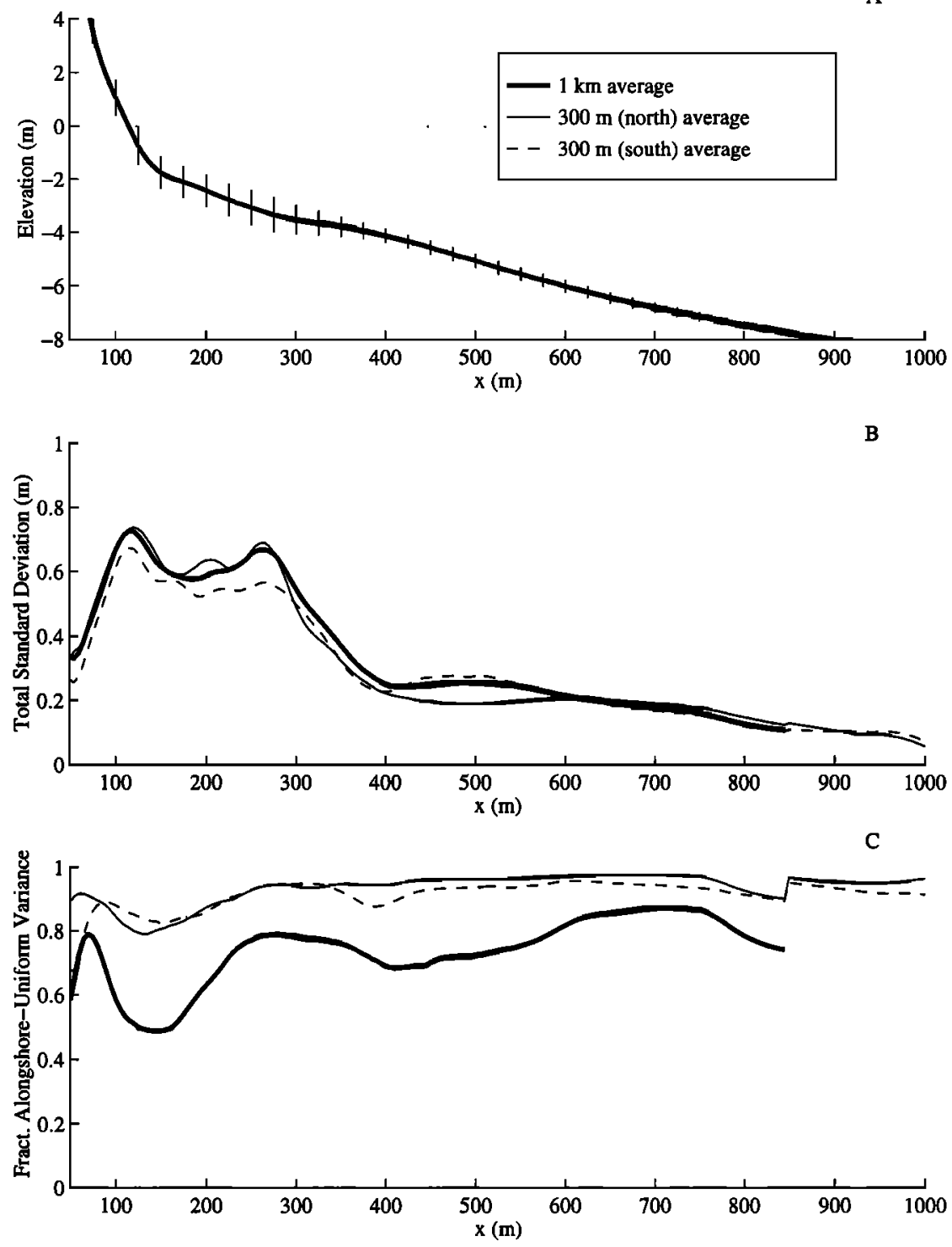

Figure 6. Alongshore-averaged profiles of the bathymetric (a) mean and (b) standard deviation and (c) fraction of alongshore-uniform variance. Profiles were estimated using observations within each of the 300 -m-wide regions and across both regions. Error bars on the mean (a) are 1 standard deviation.

where sandbars were active (between the shoreline and about $3 \mathrm{~m}$ mean depth). Between the 3- and 4-m mean depth contours the beach elevation variance dropped markedly and then decreased gradually across the remaining portion of the profile.

The profiles shown in Figure $6 \mathrm{~b}$ represent variance contributed by all alongshore length scales. The alongshore-uniform component of each bathymetric survey was extracted by alongshore averaging the deviations from the time-mean beach surface:

$$
Z_{Y}^{\prime}(x, t)=\sum_{y=Y_{1}}^{Y_{2}} Z^{\prime}(x, y, t) / N_{Y} .
$$

Plate 1 shows space-time maps (time stacks) of the alongshore-averaged deviations, corresponding to the north and south subregions. For reference, a solid white line running roughly parallel to the time axis marks the measured shoreline (0.0-m elevation) and horizontal lines mark January 1 of each year. Warm colors correspond to elevations above the timeaveraged profile (sandbars), and cold colors correspond to elevations below the mean (troughs). A striking feature in the time stacks is the coherent nature of sandbars, which can be tracked for nearly a decade in some cases. The four bars identified in the north region are described in detail in section 3.4 , and their response is compared to the model (equation (1)) in section 4.

Next, the temporal variance of the alongshore-uniform bathymetric component was estimated within and across the north and south regions:

$$
s_{Y}^{2}(x)=\sum_{i=1}^{N_{t}} Z_{Y}^{\prime}\left(x, t_{t}\right)^{2} / N_{t}
$$

Figure $6 \mathrm{c}$ shows these profiles, normalized by the total variance $\left(S_{Y}(x)\right)$. In both the north and south regions the alongshore- 
Duck, 1981 to 1996 ( $y=776$ to $1096 m)$

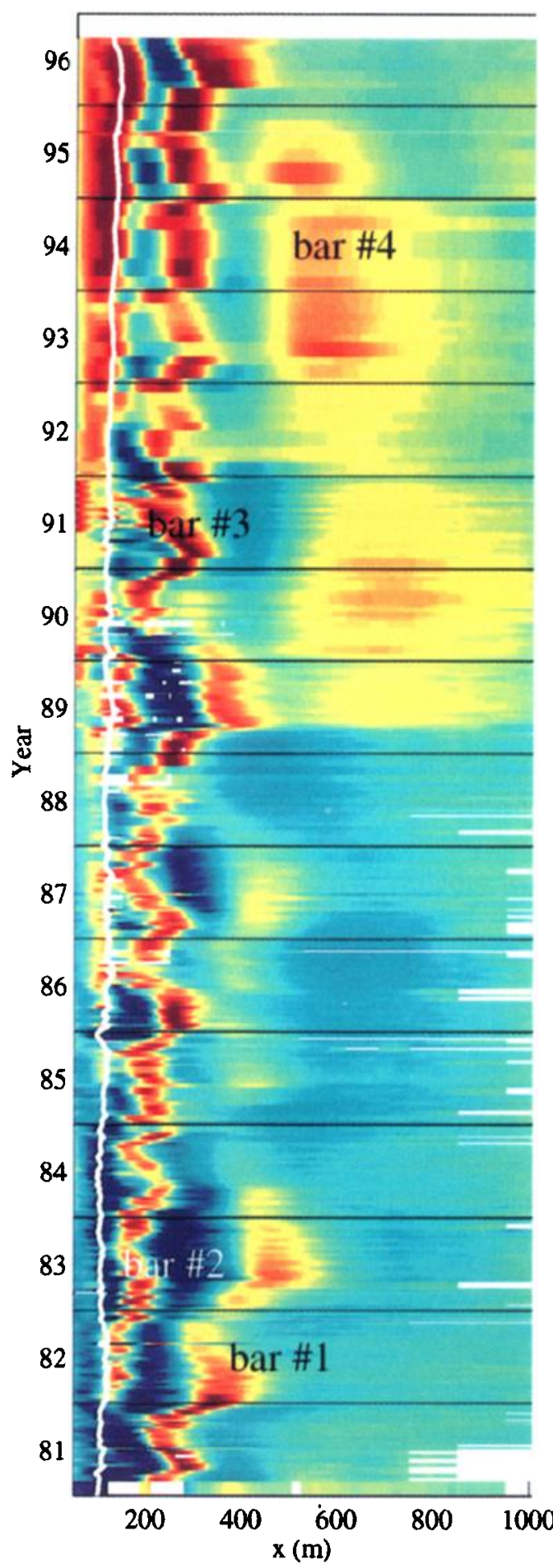

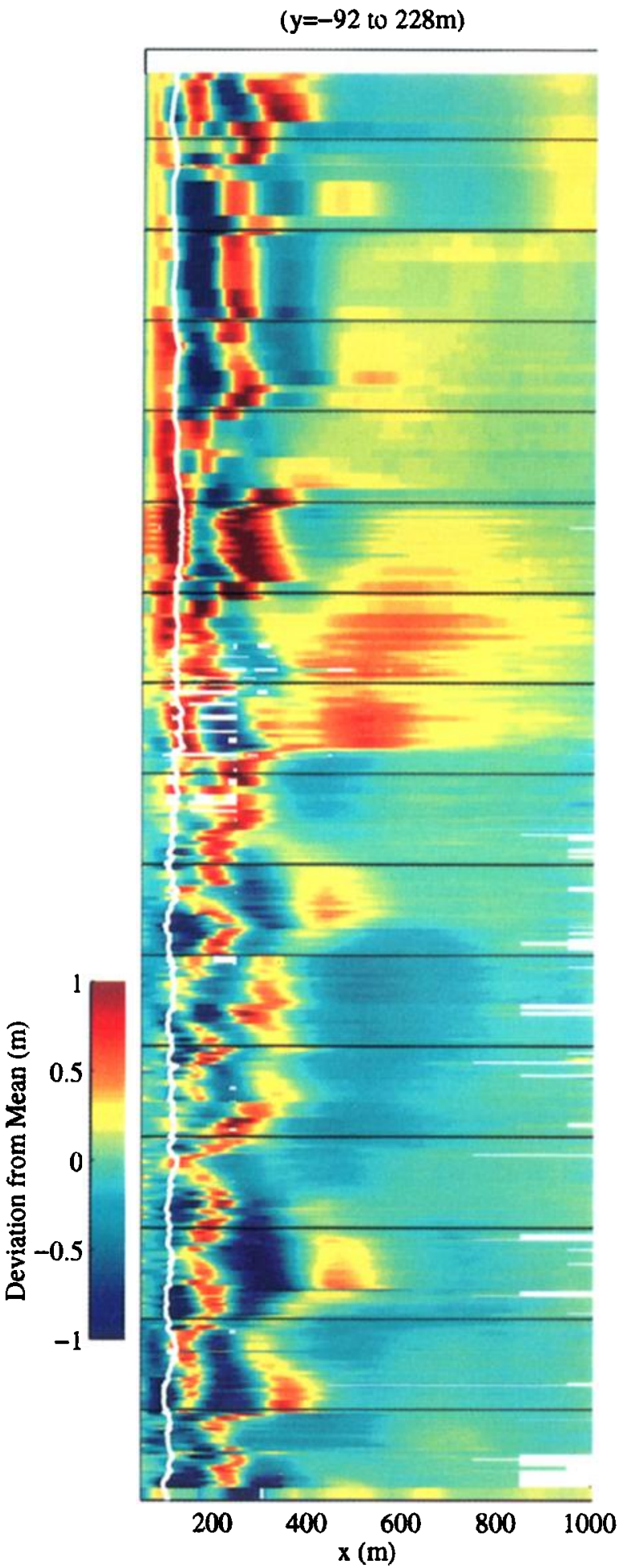

Plate 1. Time stack of alongshore-averaged deviations from 16-year mean profile. The solid white line running along the time axis is the position of the shoreline (0.0 National Geodetic Vertical Datum (NGVD)). Individual sandbar crests are labeled in the north study region $(y=776$ to $1096 \mathrm{~m})$. Blank regions indicate missing observations (interpolation error $>0.2 \mathrm{~m}$ ). 


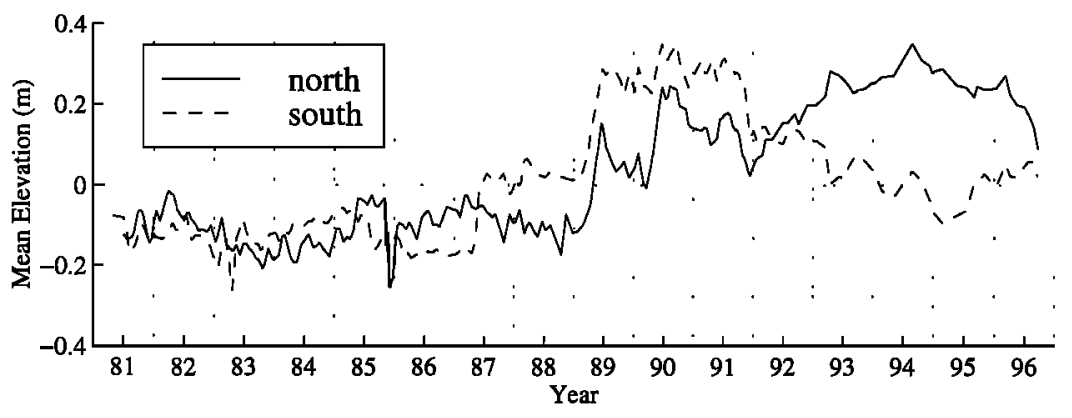

Figure 7. Time series of spatially averaged profile deviations (the time-mean elevation has been removed). The statistics were estimated separately over the north and south regions (Figure 5a). Observations between +2 and $-8 \mathrm{~m}$ mean elevations were included in the cross-shore average.

uniform mode explained more than $80 \%$ of the total profile variance. The fraction of alongshore-uniform variance was lowest $(80 \%)$ slightly seaward of the mean shoreline position at a mean depth of about $1 \mathrm{~m}$ and was highest at the seaward limit of the surveys. When averaged over both north and south regions, the variance fraction explained by the alongshoreuniform component was reduced to $50 \%$ near the shoreline. Thus much of the beach variability near the shoreline must be attributed to features with alongshore scales less than $1 \mathrm{~km}$. (It is not known how the presence of the pier affects the degree of alongshore uniformity.) A step-like increase in the percentvariance profile occurred at the typical seaward limit of the monthly surveys (about $x=800$ ). Seaward of $800 \mathrm{~m}$, only two profiles in each region were surveyed (separated by $100 \mathrm{~m}$ ), aliasing short-scale variability.

Profile deviation data shown in Plate 1 may be averaged in the cross-shore as well. This allows us to determine the degree to which mass was conserved in the sample region (Figure 7). If mass were conserved, we would expect to see relatively constant spatially averaged elevations through time. Prior to 1989 , only relatively small changes occurred in the total sediment volume. However, 1989 saw a significant gain in sediment, averaging $20-30 \mathrm{~cm}$ over the region. In the following years the total sand volume continued to fluctuate, although not with the abruptness of the 1989 changes. In addition, fluctuations in the 1990 s were not uniform between the north and south regions. It is possible that a cross-shore sediment influx from depths greater than $8 \mathrm{~m}$ contributed to these changes, since significant elevation changes occurred at the seaward limit of the surveys (Plate 1).

\subsection{Temporal Patterns of Variability}

Nearshore bathymetry varies on a continuum of timescales. We chose to split this range into interannual (longer than 1 year) and intra-annual (equal to or shorter than 1 year) components. Intra-annual timescales include the seasonal cycle and shorter fluctuations associated with passing storms, which dominated the wave-forcing signal. The relative importance of interannual and intra-annual timescales was evaluated from time series of profile elevations, extracted from the alongshore-averaged profiles (i.e., the data presented in Plate 1).

Time series were extracted at cross-shore locations, which corresponded to mean depths of $0 \mathrm{~m}$ (near the shoreline), $3 \mathrm{~m}$ (inner bars), $4 \mathrm{~m}$ (outer bars), and $6 \mathrm{~m}$ (seaward of most bars). Monthly averaged time series were constructed by first applying a Hanning (cosine squared) filter with a width of 30 days to the original (unequally sampled) time series. The filtered ob- servations were then linearly interpolated to an equally spaced time series with a sample interval of $\mathbf{3 0}$ days. Hereinafter, the resulting time series are called "monthly averaged," although the filtering operation was imperfect, especially in cases where the sample spacing exceeded 60 days (the filter operation did nothing in these cases).

Figure 8 shows the resulting time series. Cross-shore differences in beach response were evident. Near the shoreline the beach elevation changed significantly on both intra-annual and interannual timescales. In contrast, at the 4- and 6-m mean depth locations, intra-annual variations were strongly damped and the beach response had a "sawtooth" appearance. This response was correlated across both north and south regions and in the cross-shore direction. Rapid elevation changes typically corresponded to rapid seaward migration of sandbars (see Plate 1). A clear example of this occurred in late February 1989 (Figure 8), a time that had previously been observed to correspond to the transition of an inner bar to an outer bar [Lippmann et al., 1993].

The frequency content of each signal was examined by calculating the band-averaged spectra from each time series (Figure 9). At all locations, more than $70 \%$ of the bathymetric variability was attributed to frequencies lower than $1 \mathrm{cycle} / \mathrm{yr}$ (the first two frequency bands). These frequencies accounted for more than $90 \%$ of the variability at the offshore locations.

To examine the alongshore nature of variations, the squared coherence and phase shift were calculated between northsouth pairs of time series extracted from the same mean depth but separated by approximately $1 \mathrm{~km}$ alongshore. In most cases where the coherence was high, phase shifts were near zero. Thus large-scale, alongshore-progressive features (which would appear as a linear trend in the phase versus frequency) were not responsible for the long-term sandbar cycles.

Profile response in the northern region was not always coherent with the response in the southern region. At the higher frequencies ( $f>1$ cycle/yr), low coherences may have been due to the reversing migration direction of sandbars. That is, if bars simply propagated offshore and the sample locations were offset relative to the initial crest position, the coherence would be high and the phases would increase with increasing frequency. Instead, since the direction of bar migration changed, the actual phase shifts changed sign, leading to poor coherence averaged over the entire record. The alongshore coherence was poor even at low frequencies at the inner two locations. If long-term sandbar cycles were responsible for low-frequency 

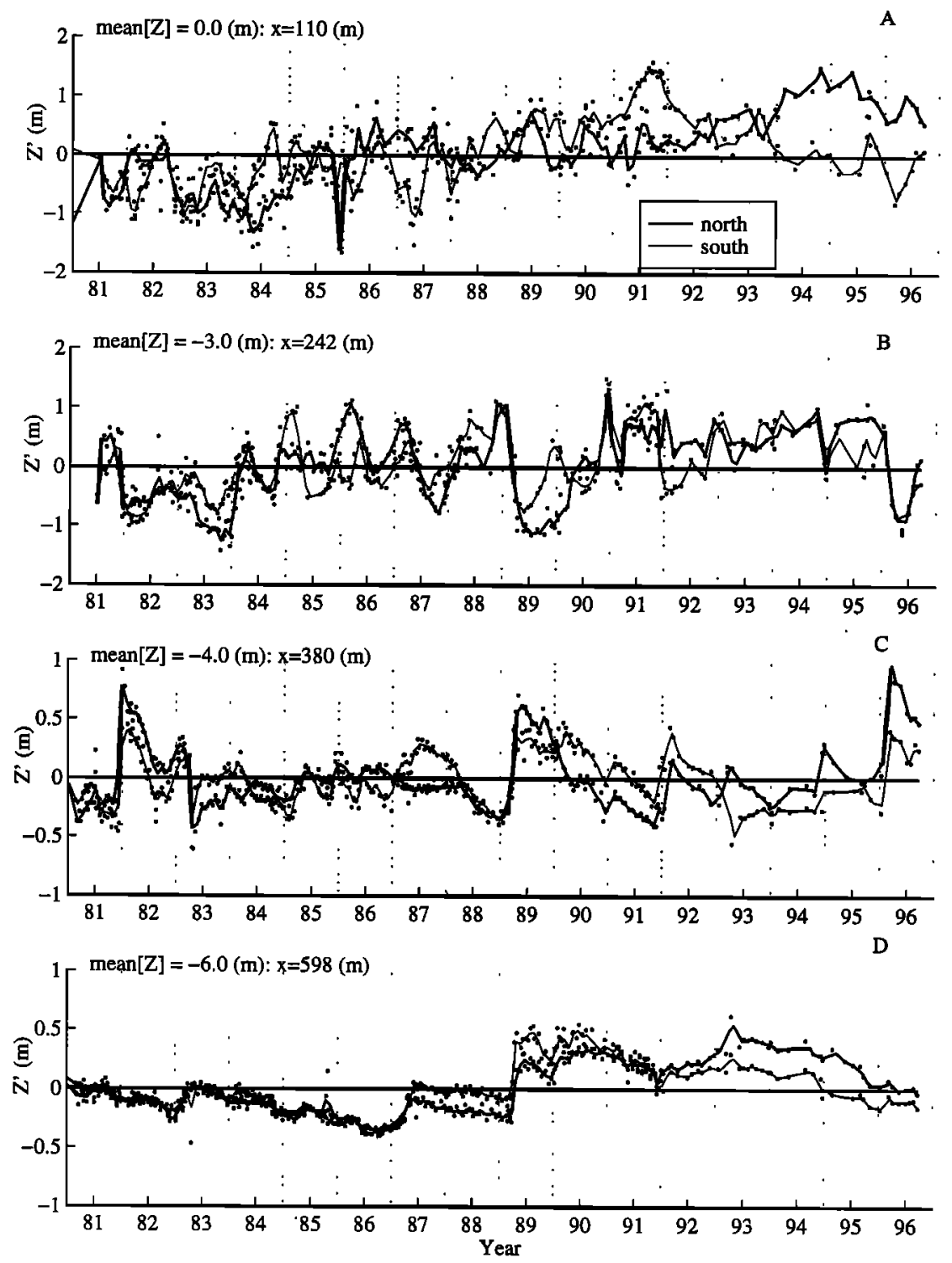

Figure 8. Time series of profile deviations, sampled at mean water depths of (a) 0, (b) 3, (c) 4, and (d) $6 \mathrm{~m}$. The time series were extracted from the alongshore-averaged profiles at fixed cross-shore locations (labeled in each panel for reference to Plate 1). Dots indicate the spatially interpolated elevations, while the lines represent the "monthly averaged" (temporally interpolated) values.

variations, then some characteristics of these cycles must have differed on either side of the pier.

Differences in beach response on either side of the pier were quantified by examining the cross-shore-lagged correlation between profiles (rather than elevations at particular points) in the north and south regions (Figure 10a). If beach response were uniform alongshore, correlations would be high (near 1) with the maximum at zero lag. Figure $10 \mathrm{~b}$ shows that while there were extensive periods of high correlation at nearly zero lag, sections of the records also showed poor correlation and/or maximum correlation at unusually high lags (Figure 10c). For instance, in early 1985 the cross-shore lag corresponding to the maximum correlation became significantly nonzero for a period of almost 2 years. The lag at maximum correlation reached a maximum value of $150 \mathrm{~m}$. Figure 4, a contour plot from December 1985, illustrates this situation. Sandbars to the north and south of the pier were nearly shore parallel, but the inner bar was absent to the north. From Plate 1 it is clear that, during this period, the bar system in the south migrated seaward while the bar to the north did not. In 1992, another episode of relative migration occurred, doubling the number of interannual bar cycles observed in the south, relative to the north region.

\subsection{Identification of Individual Sandbars}

Since alongshore-uniform response explained more than $80 \%$ of the total variance and since Plate 1 suggests that much of the variability was associated with the migration of sandbars, bar crest position provides a compact representation of morphological variability. Bar crests were identified in the present data set as maxima in spatially detrended and smoothed bathymetric deviation profiles, $Z_{Y}^{\prime}$ (see Figure 11). Using data only from the northern subregion, maxima were identified as zerodown-crossings of the profile slopes. The results obtained using 

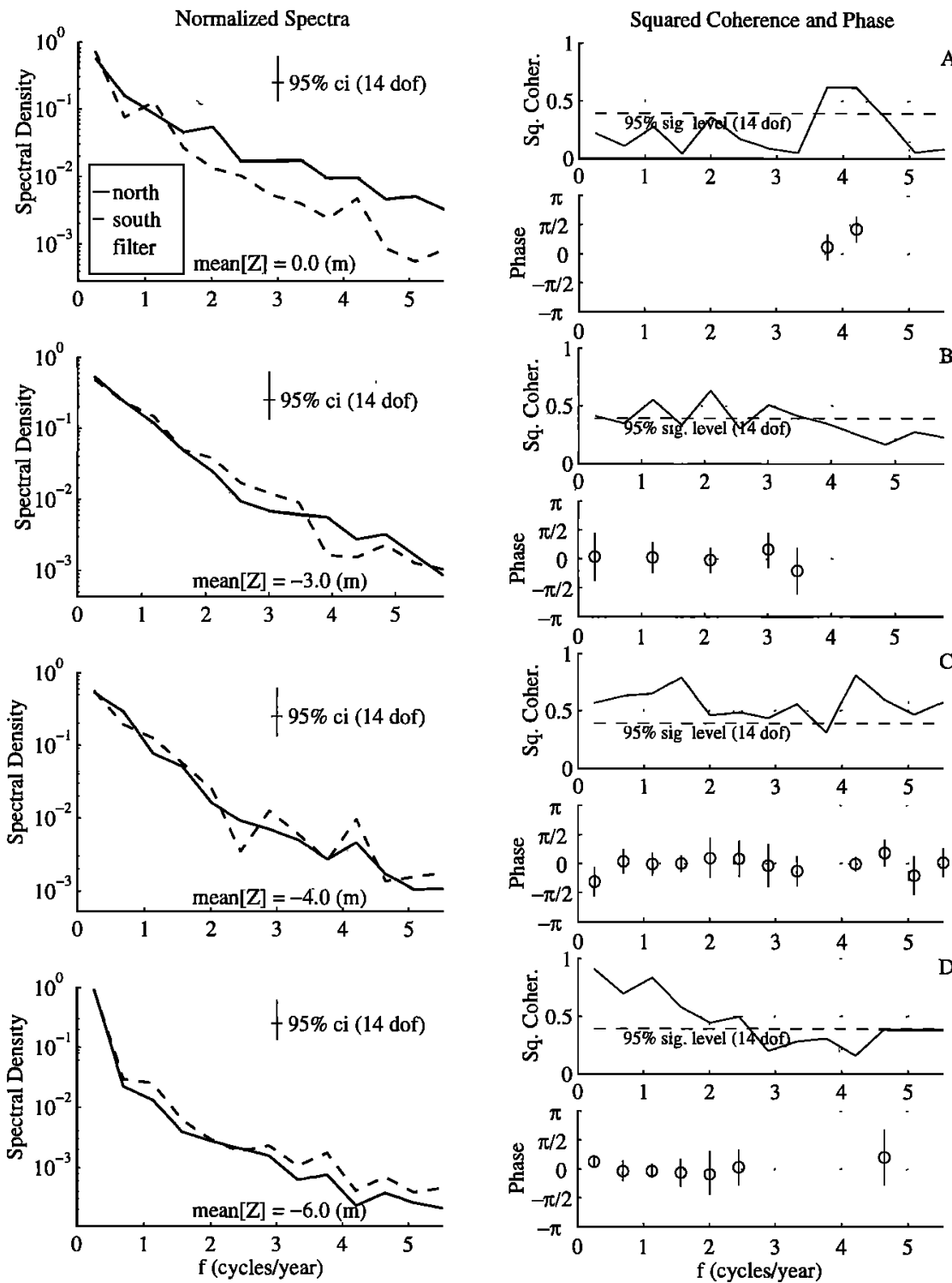

Figure 9. Power, phase, and coherence spectra corresponding to the elevation time series shown in Figures 8a-8d. The dotted line in each power spectrum plot describes the filter characteristics of the monthly averaged operation, which introduced no more than a $50 \%$ power loss at the highest frequencies. Phases are plotted only where the coherence estimates exceeded the $95 \%$ significance level.

this bar crest definition differed from the result that would have been obtained if bars were identified as elevation maxima. The difference depended only on the slope of the mean profile and was small where the mean profile's slope was small, relative to the deviation profile's slopes. No elevation maxima are found when the seaward directed slope of the mean profile exceeds the maximum landward directed slope of the deviation profile. Thus tracking crests in the deviation profile better preserved the identity of coherent bar forms, regardless of their slopes and location on the mean profile [Bowen and Huntley, 1984].

Bar length was defined as the distance between the profile minima adjacent to a crest, and bar amplitude was defined as half the mean elevation difference between minima and maxima (Figure 11b). Bar properties were estimated with a variety of other techniques, which all gave essentially the same results. Each bar crest was associated with one of four persistent sand- bars (bars 1-4, Plate 1). Stepping through the time series, each crest was assigned to the nearest, previously identified bar. Some manual intervention was required to identify bars at the beginning and end of interannual bar cycles. Bars occasionally divided into a shoreward propagating feature (called shoreward propagating accretionary waves (SPAW) by $\mathrm{K}$. M. Wijnberg and R. A. Holman (personal communication, 1998)) and an offshore propagating feature. The SPAWs were manually identified and culled from the time series. Figure 12 shows resulting time series of bar properties, smoothed to monthly values.

Most aspects of sandbar response seen in Figure 12 were consistent with the RK94 model. Bars generally formed near the shoreline (e.g., bars 2 and 3 ) and then migrated offshore (e.g., bars 1-3). The transitions of an inner bar to an outer bar occurred over periods as short as 1 year to as long as 3 years, with bar crest depth stabilizing thereafter. While bar 1 per- 

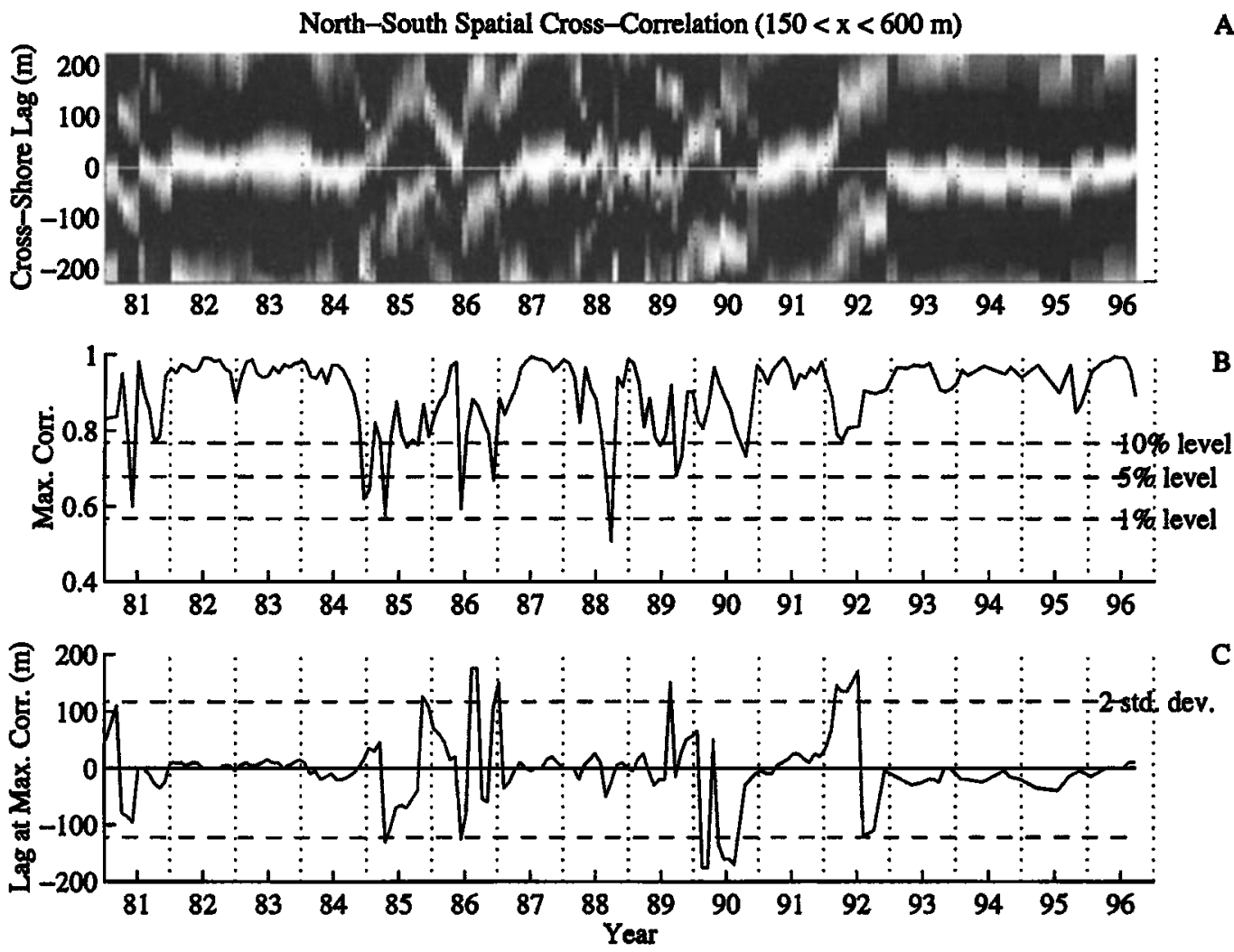

Figure 10. Time series of spatial cross-correlation between profiles (alongshore averaged) to the north and south of the pier. (a) Gray-scale map of correlation as a function of time (horizontal axis) and cross-shore lag (vertical axis). Black corresponds to correlations less than 0 , and white corresponds to a correlation of 1 . When the maximum correlation was near zero lag, bars in the north were aligned with bars in the south. The time series show the (b) maximum correlation at each time (dashed lines are labeled with the percent of observations that fell below the corresponding level) and (c) corresponding lag at maximum correlation.
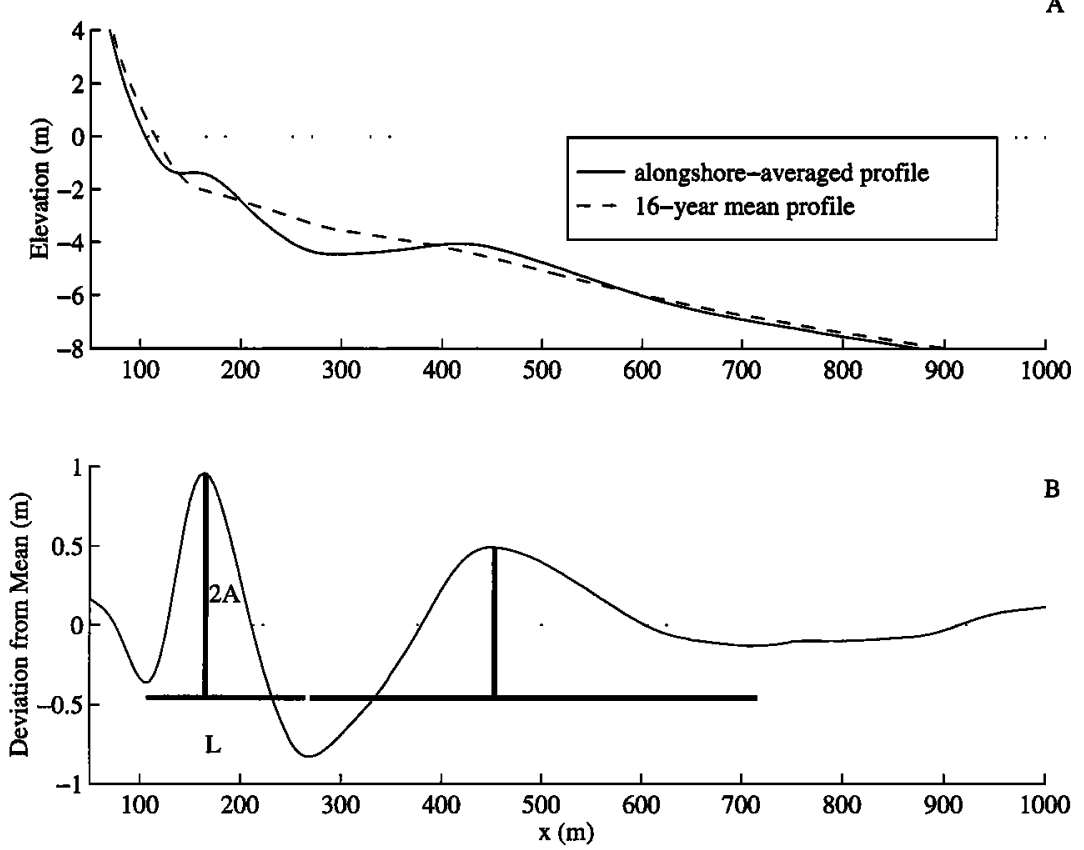

Figure 11. Estimation of bar parameters on June 13, 1983. The mean profile and a quadratic trend were subtracted from the (a) observed profile. Bars were identified in the (b) detrended deviation profile. 

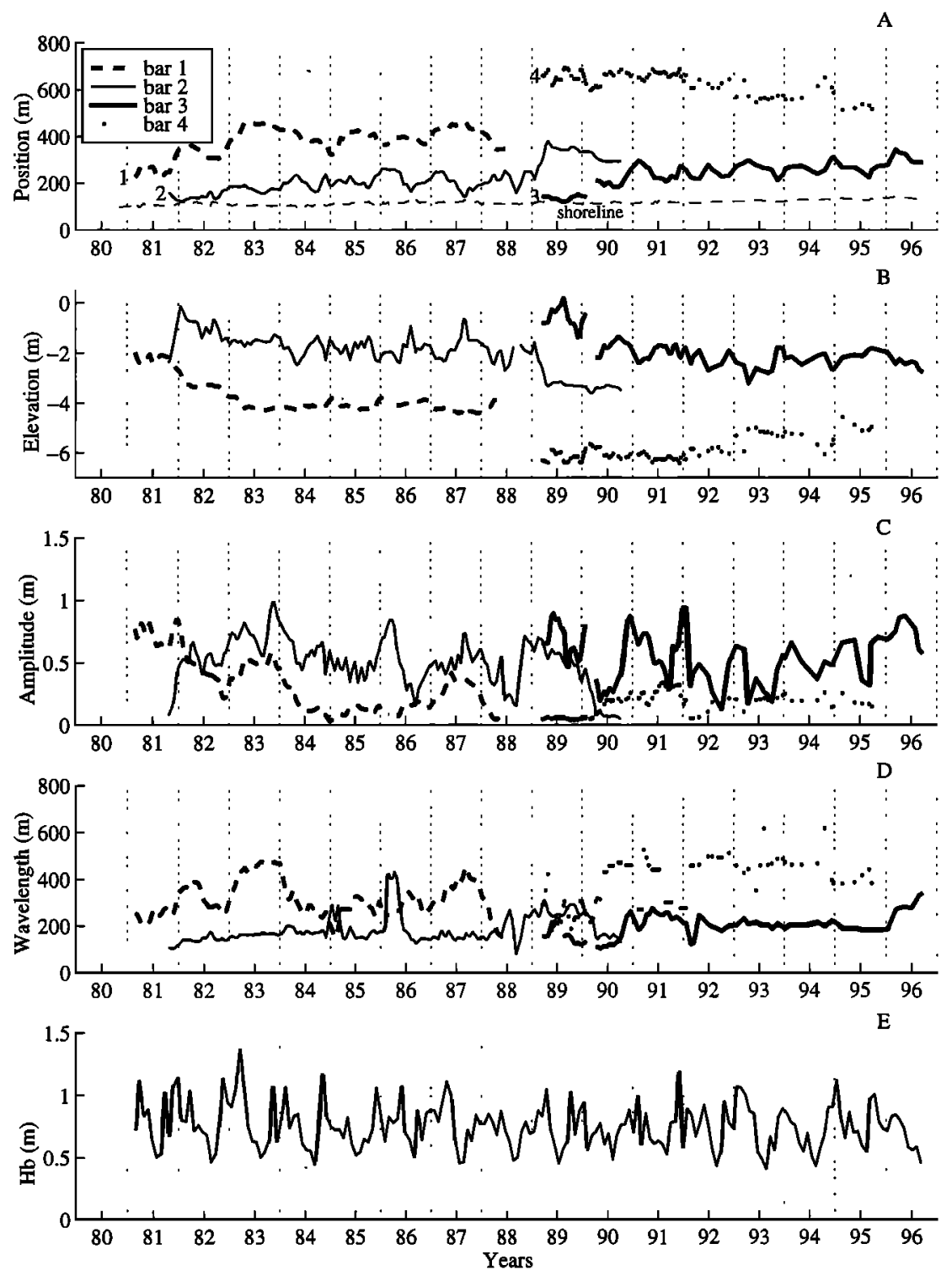

Figure 12. Time series of monthly averaged bar crest parameters, (a) position, (b) elevation, (c) amplitude, and (d) wavelength. The (e) wave height time series has been filtered as well.

sisted as an outer bar for 7 years, bar 2 decayed after spending only 2 years in the outer bar phase. Interestingly, bar decay and ultimate disappearance were clearly associated with onshore migration, conflicting with the RK94 model, which associated offshore migration with outer bar decay. Bar 4, which appeared offshore and migrated onshore, was particularly anomalous in this respect. In all cases, bar migration was dominated by interannual timescales. Bar statistics are summarized in Table 1.

The amplitudes and wavelengths of all the sandbars exhibited large fluctuations. Significant amplitude and wavelength changes occurred over timescales that were comparable to the timescales of significant bar position changes. There were occasional, striking variations in bar wavelength, which resulted when bars divided (forming SPAWs). This occurred in 1988 (bar 2) and in 1992 (bar 3). In 1986 the wavelength of bar 2 doubled, as the inner bar apparently merged with the outer bar. Although interesting, we will not examine the variations of all bar parameters. Specifically, the model that we will test does not account for any changes in bar amplitude or wavelength.

\section{Equilibrium Model Evaluation}

The equilibrium models (equations (2c) and (4f)) make specific predictions about the relationships between the wave height (the forcing) and the bar response. We chose to represent the forcing with an estimate of the rms wave height at breaking. This choice for the forcing allows us to test the breakpoint hypothesis. We assume that the wave height at breaking is proportional to the water depth $\left(H_{b}=\gamma h_{b}\right.$ [Thornton and Guza, 1982], where $h_{b}$ is the depth at breaking). Using this assumption and linear wave theory, the estimated wave height at breaking is [Komar, 1974]

$$
H_{b}=\left(\frac{\gamma}{g}\right)^{1 / 5}\left[H_{0}^{2} C_{g_{0}} \cos \left(\theta_{0}\right)\right]^{2 / 5}
$$


Table 1. Bar and Shoreline Statistics

\begin{tabular}{|c|c|c|c|c|c|c|c|}
\hline Data & $\begin{array}{l}\text { Number of } \\
\text { Observations }\end{array}$ & $\begin{array}{c}\overline{X_{c}}, \\
\mathbf{m}\end{array}$ & $\begin{array}{l}\bar{A}, \\
\mathrm{~m}\end{array}$ & $\begin{array}{l}\bar{L}, \\
\mathrm{~m}\end{array}$ & $\begin{array}{c}\bar{h}_{c}, \\
\mathrm{~m}\end{array}$ & $\begin{array}{c}\bar{C}, \\
\mathrm{~m} / \mathrm{d}\end{array}$ & $\begin{array}{c}\text { Trend, } \\
\% \text { Variance }\end{array}$ \\
\hline Bar 1 & 195 & $375(66)$ & $0.7(0.5)$ & $314(81)$ & $3.8(0.7)$ & 0.046 & 38 \\
\hline Bar 2 & 233 & $215(62)$ & $1.0(0.4)$ & $185(64)$ & $1.9(0.8)$ & 0.051 & 59 \\
\hline Bar 3 & 94 & 227 (58) & $1.1(0.4)$ & $199(54)$ & $1.9(0.7)$ & 0.057 & 59 \\
\hline Bar 4 & 85 & $634(51)$ & $0.3(0.2)$ & $369(117)$ & $5.9(0.4)$ & -0.058 & 45 \\
\hline Shore (north) & 300 & $113(9)$ & $\cdots$ & $\cdots$ & $\cdots$ & 0.004 & 51 \\
\hline Shore (south) & 328 & $113(8)$ & $\cdots$ & $\cdots$ & $\cdots$ & 0.003 & 28 \\
\hline$H_{b}$ & 5987 & $0.75^{a}(0.37)$ & $\cdots$ & $\cdots$ & $\cdots$ & $\cdots$ & 4 \\
\hline
\end{tabular}

Varıables are defined as follows: $X_{c}$, bar crest or shoreline position; $A$, bar amplitude; $L$, bar length; $h_{c}$, bar crest depth; $C$, bar migration rate (estimated from trend); and trend refers to the position data only. Overbars denote mean; values in parentheses denote standard deviations.

${ }^{a}$ Value denotes mean wave height.

where $g$ is gravity and the rms wave height $\left(H_{0}\right)$, wave group velocity $\left(C_{g_{0}}\right.$, a function of water depth and wave period), and angle of wave incidence $\left(\theta_{0}\right)$ must be measured at a wave gage. At Duck a typical value of $\gamma$ is 0.4 [Sallenger and Holman, 1985; Sallenger and Howd, 1989; Raubenheimer et al., 1996], and we used this in our calculations.

Wave height and period were recorded at several different wave gages over the period 1981-1996. When available, we used wave heights measured by a surface-piercing wave staff (gage 625) at the end of the FRF pier. This location was in relatively shallow water but was seaward of most bar crests. If data were not available from gage 625, we used data from an array of bottom-mounted pressure gages (collectively named gage 3111 , located in approximately $8 \mathrm{~m}$ depth, $1 \mathrm{~km}$ offshore), which also provided estimates of wave direction. If neither gage 625 nor gage 3111 was available, we used data from a Waverider buoy (gage 630), located $4 \mathrm{~km}$ offshore (17 m depth) and $2 \mathrm{~km}$ to the south of the research pier. Wave data were also available from a wave staff located between the shore
A
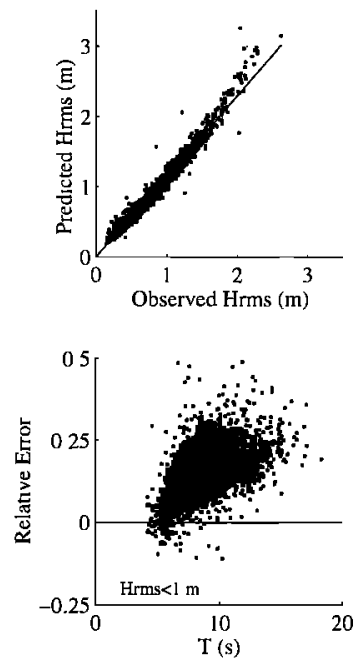

C
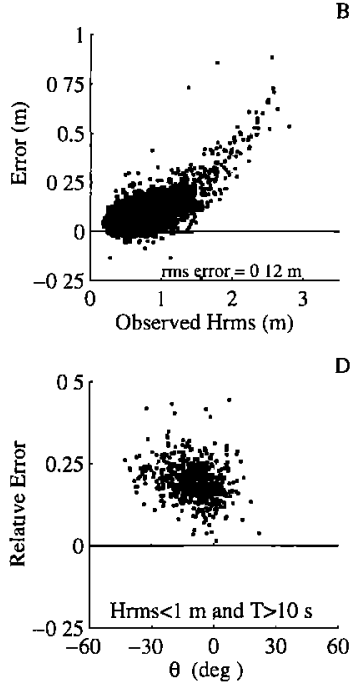
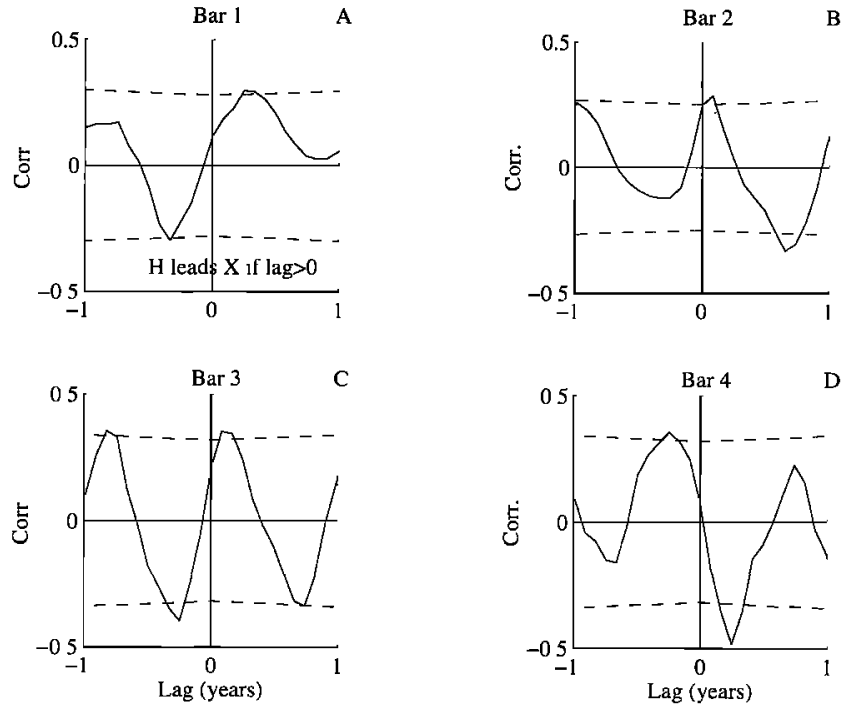

Figure 13. (a) Comparisons of the wave heights measured at gage 625 (end of pier) and linear theory predictions, which were driven by observations at gage 630 ( $4 \mathrm{~km}$ offshore). The best fit linear relationship is shown as a solid line. (b) Differences between predictions and observations. (c) Relative errors (error divided by the offshore wave height) plotted against wave period for all cases where the offshore wave height was less than $1 \mathrm{~m}$. Errors were highest for (d) long-period waves, which typically approached from the south. and the pier end (gage 641 at $x=219 \mathrm{~m}$ ). Since wave direction estimates were not uniformly available, $\theta_{0}=0$ was assumed. Using this assumption, predictions of the shoaled wave height (nonbreaking conditions) at gage 625, made using data from gage 3111 , were in error by less than $10 \%$, and errors were less than $25 \%$ using gage 630 (Figure 13).

\subsection{Constant Response Time Assumption}

The relative magnitude of the rate coefficient $\alpha_{0}$ (assumed constant for each bar) in (2c) was estimated by examining the phase shift of the bar crest location relative to the predominantly annual signal of the wave forcing. To minimize the influence of transients, a quadratic trend was removed from the observed bar position time series. Figure 14 shows the time-lagged cross correlation between the time series of wave height and detrended bar position. For each bar there were significant correlations at lags of a few months. Bar 1 showed the highest correlation at a lag of 3 months, corresponding to a phase lag of $\pi / 2$. Assuming a dominant annual forcing, the phase (in radians) is $2 \pi \mathrm{lag} / 12$ (lag in months). This is the
Figure 14. Cross correlation between monthly averaged wave heights and bar crest positions for bars (a) 1, (b) 2, (c) 3, and (d) 4 . Time series were detrended before the cross correlation was estimated. Positive lags correspond to physically meaningful correlations (wave height leads bar position). The dashed lines are $95 \%$ confidence intervals, estimated according to a scheme described in Appendix B. 
maximum predicted (equation (2c)) phase lag for bar response forced by wave height, and implies that the response time of this bar was long compared to the annual cycle (transient response could be relatively important). Bar 2 and bar 3 crest positions were both significantly correlated to wave height, at lags of 1 and 2 months. These lags correspond to normalized response times $(\alpha / \omega)$ of about 2 and 0.5 , respectively. If the bar response times were truly constant, transient behavior would be expected to persist for less than half a year (bar 2) or as long as several years (bar 3 ). The response of bar 4 lagged behind the wave height fluctuations by 3 months, suggesting that the response time was again long compared to the annual cycle. Interestingly, the maximum correlation in this case was negative and indicated that large waves were correlated with onshore migration. The fact that bars 1 and 4 had longer response times may be related to the fact that both were outer bars, which were located in greater mean water depths (Table 1) and were potentially less influenced by wave action.

\subsection{Variable Response Time Assumption}

The variable response time model (equation (4f)) was used to predict changes in bar crest position, using the measured wave height to force $X_{\text {eq. }}$. The predictions were compared to estimates made from observed changes. Estimates of changes in bar crest positions and associated migration rates (hereafter, the later are called bar velocities) were obtained from a filtered version of the bar position time series:

$$
\left[\frac{\Delta X_{c}}{\Delta t}\right]_{\text {data }}^{\iota}=\frac{1}{\left(t_{t}-t_{t-1}\right)}\left\{\left[X_{c}\right]_{\text {filtered }}^{t_{t}}-\left[X_{c}\right]_{\text {filtered }}^{t_{-1}}\right\},
$$

where the index $i$ orders the bathymetric surveys in time. The backward difference operation is accurate if bar position fluctuations have periods longer than $2 \Delta t$ ( $\Delta t$ typically 15-30 days). The filter operation used here was the same used to filter the bathymetric time series, and it eliminated variations at timescales shorter than 60 days.

Predicted changes in bar position (normalized by the time interval between surveys) were obtained by integrating the model in its nondimensional form (4f).

$$
\begin{aligned}
& {\left[\frac{\Delta X^{*}}{\Delta t^{*}}\right]_{\text {model }}^{t} }=\frac{a_{1}^{*}}{\left(t_{1}^{*}-t_{i-1}^{*}\right)} \\
& \cdot \int_{t^{*}-1}^{t_{i}^{*}}\left\{\left[X^{*} H^{* p}\right]_{\text {fillered }}^{l^{*}}-a_{2}^{*}\left[H^{* p+1}\right]_{\text {filtered }}^{*}\right\} d t^{*} .
\end{aligned}
$$

Since the bar position time series was filtered in (9a), (9b) represents the integration of the filtered version of (4f). Here $a_{1}^{*}$ and $a_{2}^{*}$ were estimated by minimizing the differences between the observed and predicted bar position changes. A nonlinear regression algorithm was used to do this.

As stated in section 2 (equations (4a)-(4c)), the nondimensional form of the model was motivated, in part, by a breakpoint hypothesis. Thus the breaking wave heights were scaled by the maximum, weighted-average breaking wave height

$$
H_{\max }=\operatorname{maximum}\left\{\left[H_{b}^{p+1}\right]_{\text {6iltered }}^{t} /\left[H_{b}^{p}\right]_{\text {filtered }}^{t}\right\} .
$$

The estimated value of $H_{\max }$ was $1.98 \mathrm{~m}$. The weighted average was used in order to be consistent with the model, which was driven by higher-order wave height products $(p=3)$. Bar positions were normalized by the corresponding estimate of the maximum surf zone width:

$$
X_{\mathrm{sz}}=H_{\mathrm{max}} /(\gamma \tan \beta),
$$

where $\tan \beta$ (0.0076) was the average beach slope over the region occupied by sandbars and $\gamma=0.4$, as in (8). This yielded a maximum surf zone width of about $700 \mathrm{~m}$. Time (in years) was scaled by the annual frequency

$$
\omega=2 \pi \mathrm{yr}^{-1} \text {. }
$$

Again, the nondimensional scales aids our interpretation of the model parameters. If $a_{1}^{*}=1$, the characteristic response time of a bar is about 1 year. If $a_{2}^{*}=1$, the equilibrium bar position corresponds to the outer edge of the surf zone; the bar migrates toward the breakpoint.

As a final step before testing the model, we determined an optimum value for the power $p$. Figure 15a shows the beach response rate plotted against the monthly averaged breaking wave height. (The response rate was represented arbitrarily by the rms of the rate of change of the bathymetry, estimated over both the north and south study regions. Profile differences were estimated for survey pairs having a sample interval less than 60 days and at least $50 \%$ coverage of the profile between 0 and $-8 \mathrm{~m}$.) From a least squares regression of the data in $\log$ space (after subtracting a noise floor) it was found that $p \sim 3$ provided the best fit to the data (Figure 15b). However, it should be noted that the results that follow are only weakly sensitive to $p$ and will be similar for any $p>0$.

4.2.1. Case 1: Bar 1 (all data). Figure 16a shows the estimated bar velocities (bar 1), plotted against wave height. A curve fit through averaged (within equally spaced wave height ranges) velocities indicates qualitative similarity to the pattern expected from the equilibrium model for $p>0$ (Figure 3). Low wave heights corresponded to small, onshore-directed bar velocities, while large wave heights tended to drive large, offshore-directed velocities.

These data were used to constrain the equilibrium model (Figure 16b). The equilibrium model explained $40 \%$ of the bar velocity variance (bar 1 ). The estimated (nondimensional) response time coefficient $\left(a_{1}^{*}\right)$ was 1.0 , with $95 \%$ confidence intervals ranging from 0.8 to 1.2 . This suggests that the characteristic bar response time was comparable to the annual timescale of the forcing. Note that under lower wave conditions, the instantaneous response time, $\left(a_{1}^{*} H^{* p}\right)^{-1}$, was longer than the timescale of the forcing (Figure 16c). Since $a_{2}^{*} \sim 1$, the predicted equilibrium position $\left[X_{\text {eq }}^{*}(t)=\right.$ $\left.a_{2}^{*} H^{*}(t)\right]$ corresponded approximately to the time-varying breakpoint. The model skill (the squared correlation between the predicted velocities and the observed velocities) was significant at the $95 \%$ level.

4.2.2. Case 2: Bar 1 (subset of data). The model was tested on a subset of the bar position time series comprising only observations over the period 1981-1983. During this period the bar migrated up to $250 \mathrm{~m}$ offshore (about half the maximum surf zone width). Figure 17 shows the observed and modeled bar velocities, which depended strongly on the wave height alone. The equilibrium model skill was again significant (explaining over $70 \%$ of bar velocity variance), and the estimated parameters were similar to the previous estimates. The model, however, clearly tended to underpredict the maximum onshore velocities.

4.2.3. Case 3: Bar 2. The tests using bars 2 and 3 were complicated by the fact that the standard wave data were measured seaward of intervening outer bars (bars 1 and 4). Under high waves (higher than about $1.5 \mathrm{~m}$, Figure 13), wave 


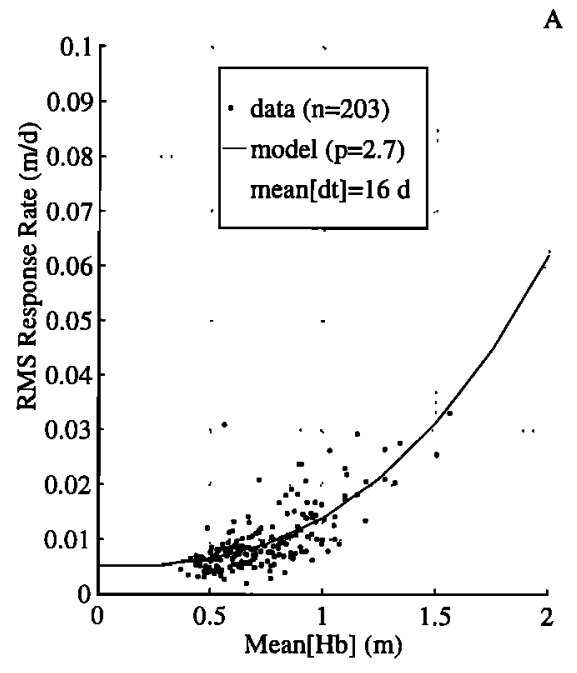

A

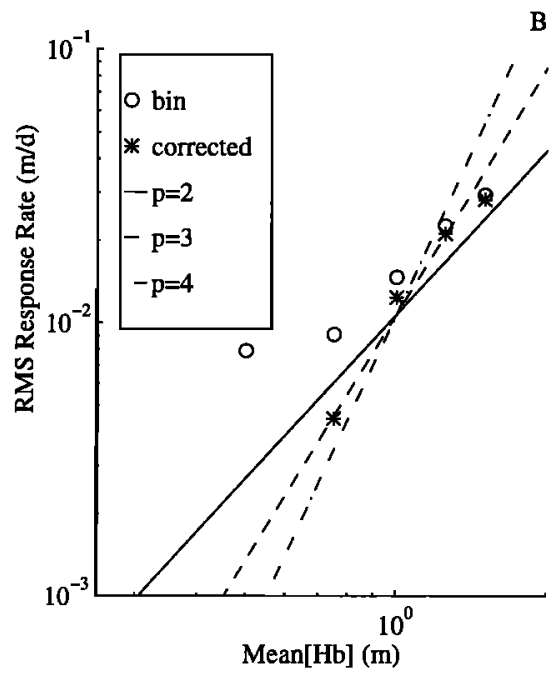

Figure 15. (a) Determination of the response time power law (equation (3a)) using the rms beach response rate (rms $[d z / d t]$ ) as a function of mean wave height. (b) The exponent, $p=2.7 \pm 0.5$, estimated from the log-transformed data. The rms response rates were corrected (asterisks) by averaging the squared response within 0.2 -m-wide wave height bins and subtracting the minimum value: $\operatorname{rms}[d z / d t]_{\text {corrected }}^{2}=\{\mathrm{rms}[d z /$ $\left.d t]^{2}-\mathrm{rms}[d z / d t]_{\min }^{2}\right\}^{1 / 2}$. The power law model (solid line in Figure 15a, rms $[d z / d t]=0.006+0.01$ mean $\left.\left[H_{b}\right]^{2.7}\right)$ was significant at better than the $95 \%$ confidence level $\left(R^{2}=0.95\right)$.

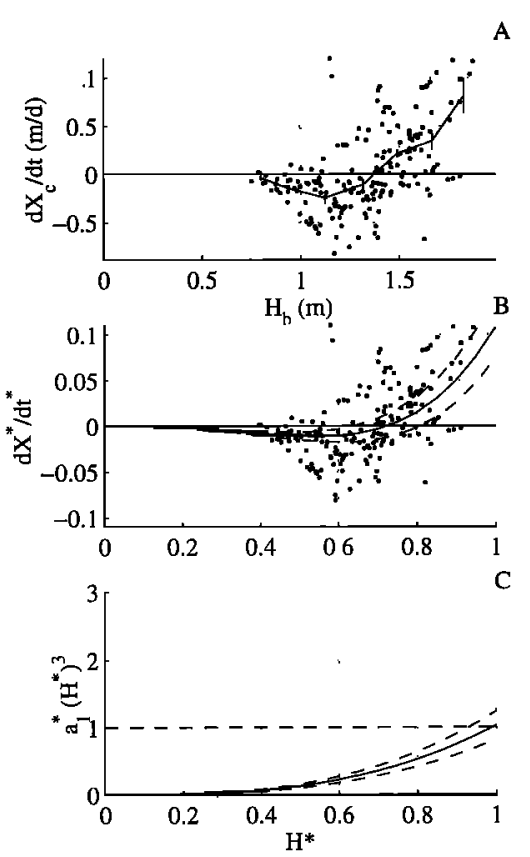

Figure 16. Bar 1 velocities examined over the period 19811988. (a) Observed (dimensional) bar velocities, plotted against wave height. The solid line is the average velocity within equally spaced wave height bins (bin width approximately $0.1 \mathrm{~m}$ ). Error bars represent the standard error about the mean velocity in each bin. (b) Nondimensional observations compared to the model predictions of velocity. The model predictions are calculated with the bar located at the mean position (solid line) \pm 1 standard deviation (dashed line). (c) Nondimensional response rate estimates as a function of wave height. The parameter estimates were $a_{1}^{*}=1.03(95 \%$ confidence interval $=0.81$ to 1.24$)$ and $a_{2}^{*}=1.20(1.15$ to 1.25). The model had significant predictive skill at the $95 \%$ significance level $\left(R^{2}=0.4, N=192\right)$. breaking over the outer bar would introduce errors in the inner bar wave height estimates. Fortunately, a wave gage (gage 641) was located just seaward of the crest of bar 2 for part of this period and could be used to test the model (Figure 18). The model skill was significant, explaining $59 \%$ of the variance. The equilibrium position scale was again consistent with the breakpoint, and the estimated characteristic response time was

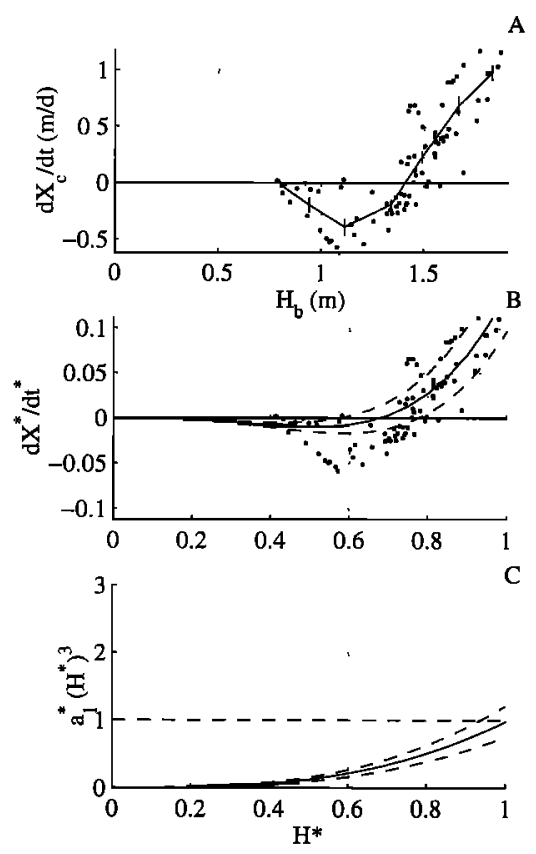

Figure 17. Same as Figure 16, but over the period 19811983. The parameter estimates were $a_{1}^{*}=0.98$ (0.75 to 1.21$)$ and $a_{2}^{*}=1.21(1.15$ to 1.28$)$ and $R^{2}=0.72(N=86)$. 

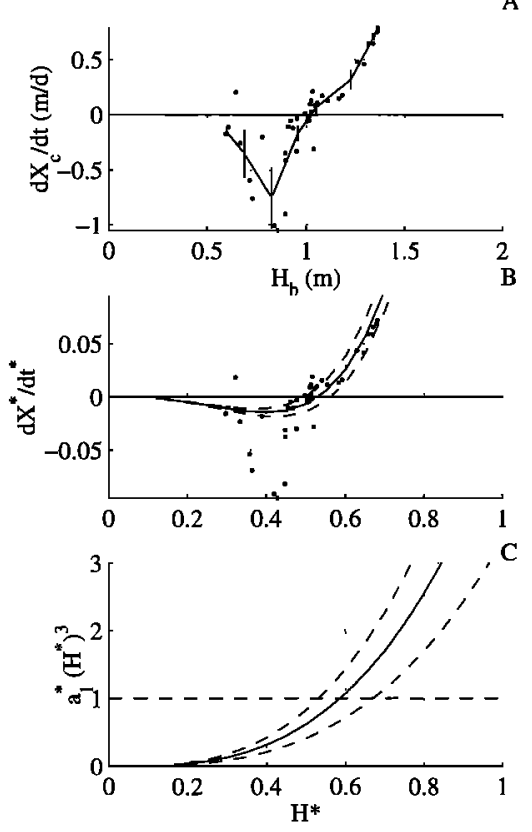

Figure 18. Same as Figure 16, but for bar 2 over the period 1985-1986. The parameter estimates were $a_{1}^{*}=4.97$ (3.32 to $6.63)$ and $a_{2}^{*}=1.09(1.02$ to 1.16$)$ and $R^{2}=0.59(N=$ 41 ). The wave heights were measured at gage 641 (available only for the period 1985-1986).

about one fifth that of bar 1 . That is, bar 2 responded to changes in the forcing much more rapidly than did bar 1 .

4.2.4. Case 4: Bar 3. The crest position of bar 3 was seaward of the inner wave gage but shoreward of bar 4 , where wave breaking occurred. Thus the predicted wave heights

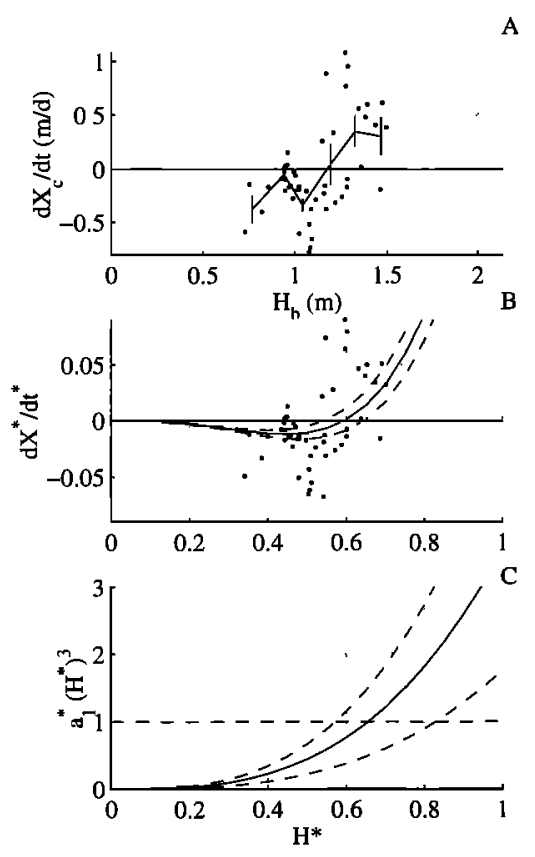

Figure 19. Same as Figure 16, but for bar 3 over the period 1990-1996. The parameter estimates were $a_{1}^{*}=3.54$ (1.75 to 5.23) and $a_{2}^{*}=1.00(0.93$ to 1.08$)$ and $R^{2}=0.27(N=$ 52 ). The wave heights were measured at gage 625 (pier end), but only heights less than $1.5 \mathrm{~m}$ were used. based on pier-end observations were not necessarily representative of the wave conditions in the vicinity of bar 3 . As a result, the model skill was not significant in the bar 3 case unless it was applied to mild wave conditions. Neglecting the data for which wave heights were greater than $1.5 \mathrm{~m}$, the model skill was again found to be significant ( $27 \%$ of variance explained, Figure 19). Again, the equilibrium position scaled consistently with surf zone width. The characteristic response time was about 0.3 years, indicating that bar 3 responded more rapidly than bar 1 but slower than bar 2 .

4.2.5. Case 5: Bar 4. The equilibrium model did not fit well the velocity estimates from bar 4 (Figure 20). This bar was usually seaward of the estimated outer edge of the surf zone. The band-averaged velocity curve (Figure 20a) suggests a qualitative similarity to the equilibrium model in the regime where the wave heights were always smaller than the equilibrium height. The attempt at constraining the model yielded large error bounds and nonphysical estimates of both model parameters.

In a final test we used (9b) to predict bar crest position time series, forced by observed wave heights. Figure 21 presents the results for bar 1 . The bar was initialized with the first observed position, and a fourth-order Runge-Kutta scheme was used to integrate the differential equation. The example presents the results based on calibrating the model over the entire 7 years of observations. The bar crest position prediction skill was 0.77 (77\% of the predicted variability was correlated to the observations). Predictions made when only the first 3 and last 3 years of observations were used to calibrate the model also led to predictions that recovered between $70 \%$ and $80 \%$ of the observed variance. The model predicted the main features of the long-term behavior. However, it did not capture some details of the short-term fluctuations. In December 1984, for example, the observed and predicted migration had opposite signs. This was a time when the bar amplitude nearly vanished.

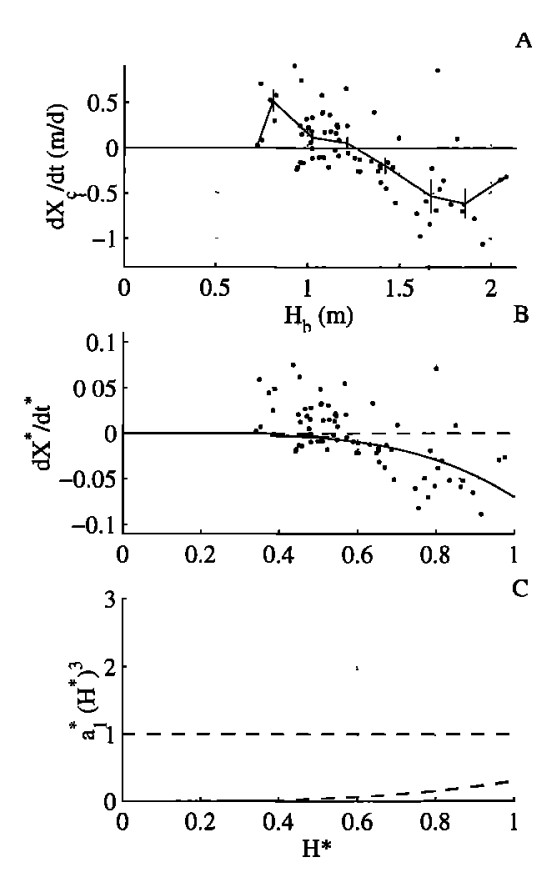

Figure 20. Same as Figure 16, but for bar 4 over the period 1990-1996. The parameter estimates were $a_{1}^{*}=0.01(-0.29$ to 0.31$)$ and $a_{2}^{*}=-32(-1200$ to 1200$)$ and $R^{2}=0.25$ $(N=74)$. (The model parameters were not well constrained.) 


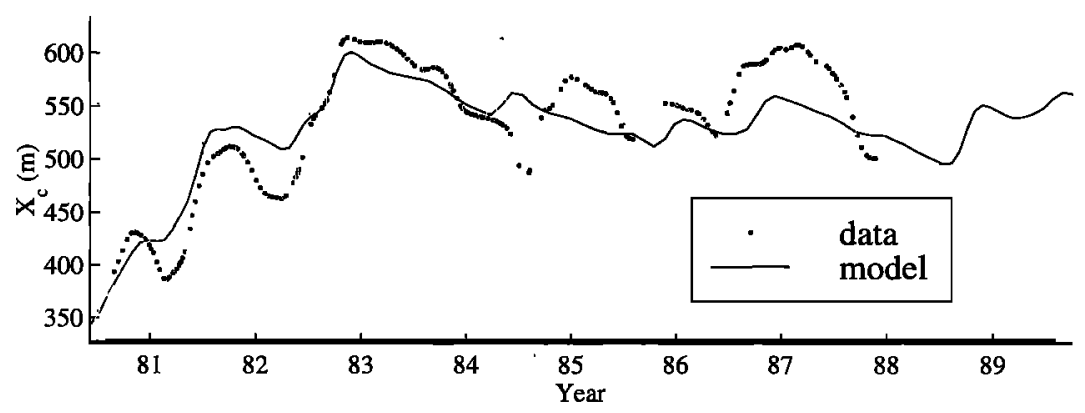

Figure 21. Examples of observed and predicted bar crest positions (bar 1). The model was calibrated using all the data.

\section{Discussion}

There is little doubt that the primary forcing for sandbar variability comes either directly or indirectly from offshore waves. Moreover, variations in ocean wave energy occur on storm and seasonal scales, with very little statistical variation from year to year (e.g., Figure 2 and Table 1). Thus it is one of the paradoxes of nearshore processes that sandbar variability is predominantly interannual in the face of this intra-annual forcing.

The model herein provides a simple solution to this problem. The proposed model suggests that sandbar migration is in the direction of an equilibrium position, consistent with traditional equilibrium thinking. However, an additional feature of the model is that the rate of migration also depends on wave height. The introduction of this rate term has two consequences. First, it yields a phase lag between variations in wave forcing and bar response that is consistent with observations of intra-annual variations (Figure 14). Second, a finite response time implies that transients in the system, such as the generation of a new sandbar at a location that is far from its equilibrium location, can take a substantial amount of time to decay, yielding potentially large interannual signals. From the data, response time estimates were found to range from 0.2 to 1 year, with the longest response time associated with an outer bar. This suggests that outer bars may be more likely to exhibit a transient component of response and is consistent with the greater dominance of interannual variance at greater depths.

The breakpoint has been suggested in previous studies as a location for bar formation, primarily because wave breaking can drive processes such as undertow. It is suggested that undertow leads to sediment convergence at the breakpoint, forming the bar. The validity of this theory has not been demonstrated, although undertow has been linked to offshore bar migration [Thornton et al., 1996]. The model presented here makes no assumption about the role of breaking per se, just that the processes that drive bar response can be scaled by wave height. However, when the data were analyzed for a best fit estimate of $a_{2}^{*}$, the predicted equilibrium location was found to be consistent with the wave breakpoint.

While this model is quite successful in being able to predict the evolution of a bar system through both a transient period as well as subsequent annual cycles, it does not explain the origin of the transients. The formation of sandbars, usually near the shoreline, and the decay of bars offshore remain observed but not well-explained phenomena that deserve much further research.

\section{Conclusions}

We have analyzed 16 years of surveyed beach elevations sampled at the Army Corps of Engineers' Field Research Facility, located on the U.S. Atlantic coast. Surveys were conducted within a region that spanned approximately $1 \mathrm{~km}$ alongshore and $1 \mathrm{~km}$ cross-shore and extended to depths greater than $8 \mathrm{~m}$. This site typically had one or two sandbars, which varied from shore parallel to irregular. The 16-year mean and variance of the surveyed bathymetry were mostly homogeneous in the alongshore direction, except for anomalies near a pier (variance increased by factor of 2). In the cross-shore direction the variance was highest between the mean shoreline position and a mean depth of $3 \mathrm{~m}$. Greater than $80 \%$ of the elevation variance was alongshore uniform within 300-m-wide (alongshore) subregions to the north and south of the pier. Between $50 \%$ and $90 \%$ of this variance was explained by alongshore-uniform response over the approximately $1 \mathrm{~km}$ alongshore span of the surveys (omitting the central $400 \mathrm{~m}$ ). Alongshore variability was highest near the shoreline.

The incident wave height variance was dominated by frequencies at or higher than 1 cycle/yr ( $96 \%$ of variance), while more than $80 \%$ of the bathymetric variance at all cross-shore locations was explained by frequencies lower than 1 cycle/yr. Long-term sandbar cycles were at least partly responsible for the low-frequency variability. Three of the four sandbars in the northern half of the study area exhibited interannual cycles consisting of sandbar formation, seaward migration, and offshore decay. Similar patterns were observed in the south half, although two additional sandbar cycles occurred there.

An empirical, equilibrium model was formulated, which explained interannual sandbar response driven by predominantly annual forcing. The model assumed that bars migrate toward an equilibrium position that is scaled by wave height. Additionally, it assumes that bar migration occurs at a rate that is proportional to the wave height raised to the $p$ th power ( $p=$ 3 yielded the best fit). The response of the bar position is phase lagged and damped, relative to the dominantly annual wave forcing. If the characteristic bar response time is long relative to the timescale of the forcing, any transients introduced into the system may persist for many cycles of the forcing. In addition, introduction of a wave height dependent response time shifts the mean bar position (after decay of a transient response) toward the equilibrium position associated with the maximum wave height. Transient bar behavior could be introduced when bars form near the shoreline or when outer bars 
decay and inner bars face a changed wave climate. The model did not contain a mechanism for introducing these transients.

Two free parameters, a characteristic response time and an equilibrium position scale, were estimated by minimizing the squared deviation between the equilibrium model prediction and the observed bar velocities. The calibrated model explained up to $80 \%$ of the observed bar position variability and between $25 \%$ and $70 \%$ of the bar velocity variance of the three sandbars that were the focus of this study. The estimated response times for the three bars varied between 0.2 and 1 times the dominantly annual timescale of the forcing. Outer bars had longer response times. The estimated equilibrium location was consistent with a breakpoint position.

\section{Appendix A: Interpolation Scheme}

The (sub)optimal interpolation scheme employed the following equations.

$$
Z_{t}^{t}=\bar{Z}_{t}+\sum_{j=1}^{J}\left[W_{t \jmath}^{t}\left(\hat{Z}_{j}^{t}-\bar{Z}_{j}\right)\right]
$$

where $Z_{t}^{t}=Z\left(x_{l}, y_{\imath}, t\right)$ and $\hat{Z}_{j}^{t}=\hat{Z}\left(x_{j}, y_{j}, t\right)$ denote interpolated and observed elevations, respectively, at a set of discrete spatial coordinates (the $i$ th coordinate is given by $x_{\ell}$, $y_{\imath}$ ) and discrete times $(t)$. The cross-shore direction corresponds to $x$; the alongshore direction corresponds to $y$. Each time corresponds to one beach survey. Interpolation weights $\left(W_{l j}^{t}\right)$ ideally produce interpolates that minimize the squared deviation between the true and interpolated bathymetry.

The interpolated elevations were calculated as corrections to a spatially smooth estimate of the time-averaged elevation

$$
\bar{Z}_{k}=\frac{1}{N_{t}} \sum_{t=1}^{N_{t}} \frac{1}{N_{k}^{t}} \sum_{j=1}^{N_{\text {cho }}^{t}}\left(\Pi_{j k} \hat{Z}_{j}^{t}\right)
$$

The smoothing operation utilized a boxcar data window,

$$
\begin{gathered}
\Pi_{j k}=1 \text { if }-L_{x} \leq\left(x,-x_{k}\right) \leq L_{x}, L_{y} \leq\left(y_{j}-y_{k}\right) \leq L_{y} \\
\Pi_{j k}=0 \text { otherwise. }
\end{gathered}
$$

The summations are over all $N_{t}$ observation times and all $N_{\text {obs }}^{t}$ samples and are normalized by the number of observation times and number of samples used; that is,

$$
N_{k}^{t}=\sum_{j=1}^{N_{\mathrm{obs}}^{t}} \Pi_{j k}
$$

$L_{x}(=50)$ and $L_{y}(=200)$ are cross-shore and alongshore scales, respectively, of spatial smoothing. The mean elevation was removed from the observations before interpolation and must be added back to the interpolated values. Thus each index $k$ can refer to either an observation or interpolation location.

The calculation of the interpolation weights depended on two, imposed (Gaussian) models for the spatial covariance between observed elevations and unknown grid elevations $\left(R_{j^{\prime} t}^{t}\right)$ and the covariance between all observed elevations $\left(\hat{R}_{j, j}^{t}\right)$ :

$$
R_{f^{\prime} t}^{t}=\left[\hat{S}_{J^{\prime}}^{2}-\left(\varepsilon_{j^{\prime}}^{\prime}\right)^{2}\right]^{1 / 2} \hat{S}_{\iota} \exp \left\{-\left[\frac{\left(x_{\imath}-x_{f^{\prime}}\right)^{2}}{\left(L_{x}\right)^{2}}+\frac{\left(y_{\imath}-y_{J^{\prime}}\right)^{2}}{\left(L_{y}\right)^{2}}\right]\right\}
$$

$$
\begin{array}{rl}
\hat{R}_{j^{\prime} \jmath}^{\prime}=R_{\jmath^{\prime}}^{t}+\left(\varepsilon_{\jmath}^{t}\right)^{2} \delta_{j^{\prime}}, \\
\delta_{J^{\prime}}=0 & j \neq j^{\prime} \\
\delta_{J^{\prime} \jmath}=1 & j=j^{\prime}
\end{array}
$$

The Gaussian-shaped covariances impose a spatial filter that significantly damps features with cross-shore length scales $<L_{x} / 2$ or alongshore length scales $<L_{y} / 2$.

Inputs to the covariance models included smooth estimates of the temporal bathymetric variance $\left(\hat{S}_{k}^{2}\right)$ at both observation and grid locations and estimates of the observation error variance at observation locations only $\left(\varepsilon_{j}^{l}\right)^{2}$. The estimate of the spatially smooth, temporal variances was

$$
\hat{S}_{k}^{2}=\frac{1}{N_{t}} \sum_{t=1}^{N_{t}} \frac{1}{N_{k}^{t}} \sum_{j=1}^{N_{\mathrm{obs}}^{t}}\left[\Pi_{j k}\left(\hat{Z}_{j}^{t}-\bar{Z}_{k}\right)^{2}\right] \text {. }
$$

A spatially smooth estimate of the unresolved component of the bathymetric variability (called observation error variance) at the $k$ th observation location was defined operationally as

$$
\left(\varepsilon_{k}^{t}\right)^{2}=\frac{1}{N_{k}^{t}} \sum_{j=1}^{N_{\text {obs }}}\left[\Pi_{j k}\left(\hat{Z}_{j}^{t}-Z_{j}^{t}\right)^{2}\right]
$$

The delta function in (A5a) and (A5b) maps this unresolved component of variance to a "white noise" spectrum. As the observation error increases, the estimated (interpolated) elevations approaches the mean elevations.

Initially, $\left(\varepsilon_{t}^{t}\right)^{2}$ is unknown, since it depends on interpolated elevations. Its value was determined iteratively. For the initial interpolation ( $n=1)$, interpolated bathymetry was estimated using a value of $\varepsilon_{j}^{t}$ equal to $10 \mathrm{~cm}$ (equal to the known measurement error). Then, the resulting interpolates were used to reestimate $\varepsilon_{j}^{t}(n)$. The iterations were halted when $\left\{\left[\left(\varepsilon_{j}^{t}\right)^{2}\right]_{n}-\right.$ $\left.\left[\left(\varepsilon_{j}^{t}\right)^{2}\right]_{n-1}\right\} / \hat{S}_{J}^{2}<0.1$ or $n=10$. Typically, two iterations sufficed.

The interpolation weights were computed from the covariance models.

$$
W_{y j}^{t}=\sum_{j^{\prime}=1}^{J^{\prime}}\left\{\left[\hat{R}_{j^{\prime}}^{t}\right]^{-1} R_{j^{\prime},}^{t}\right\}
$$

where []$^{-1}$ refers to the matrix inverse. Because matrix inversions were computationally demanding, overlapping subsets of limited sample size (typically, $J^{\prime}<300$ ) were used. Also, to alleviate inconsistencies between the true and model covariance structure, the matrix inverse was approximated using singular value decomposition to recover at least $99 \%$ of the covariance [Ooyama, 1987].

Finally, interpolation errors resulted from measurement error, unresolved morphology (e.g., megaripples), and the mismatch between the Gaussian and true covariances. The expected mean square interpolation error estimate

$$
\left(E_{\imath}^{t}\right)^{2}=\hat{S}_{\imath}^{2}-\left(\varepsilon_{\imath}^{t}\right)^{2}-\sum_{\jmath=1}^{J}\left(W_{\imath}^{t} R_{\imath}^{t}\right)
$$

represents the expected mean square deviation between the interpolated surface and the smooth version of the actual beach surface. Here $\left(E_{\imath}^{t}\right)^{2}$ is the difference between the total variance of the smooth surface (the difference between the 
first two terms on the right-hand side of (A9)) and the variance actually recovered by the interpolation process (the last term).

\section{Appendix B: Significance of Correlation Estimates}

Consider two time series that are uncorrelated. We wish to estimate a critical correlation value, $\rho_{\text {crit }}\left(\alpha, n^{*}\right)$, such that the probability is $\alpha$ that an estimate of the correlation exceeds this level by chance, owing to sampling errors in the sample statistics. Thus, if a correlation estimate exceeds the critical value, we may reject, with $100(1-\alpha)$ percent confidence, the hypothesis that the true correlation is, in fact, zero. Using knowledge of the distribution of correlation estimates, we can estimate the critical value. In applications to real observations the number of observations $n$ usually exceeds the true degrees of freedom $n^{*}$ because observations are serially correlated (i.e., not statistically independent) [Jenkins and Watts, 1969, p. 340]. We present a simple scheme for estimating the true degrees of freedom associated with tests for significance of correlation estimates.

Let $\hat{\rho}$ be a sample estimate of the correlation between time series $x_{i}$ and $y_{i}$ :

$$
\hat{\rho}=\sum_{i=1}^{n}\left[\left(x_{t}-\bar{x}\right)\left(y_{t}-\bar{y}\right)\right] /\left[\sum_{i=1}^{n}\left(x_{t}-\bar{x}\right)^{2} \sum_{i=1}^{n}\left(y_{t}-\bar{y}\right)^{2}\right]^{1 / 2},
$$

where $n$ is the number of observations and the overbar indicates an average over $n$. In the case of zero true correlation between $x$ and $y, \hat{\rho}$ is normally distributed with zero mean and variance of $1 / n^{*}$ [Jenkins and Watts, 1969, p. 187]. Thus we can define the random variable

$$
\hat{q}=\hat{\rho}^{2} n^{*},
$$

which is chi-square distributed with 1 degree of freedom $\left(\chi_{1}^{2}\right)$.

We want to test the null hypothesis that a sample correlation estimate belongs to a population having zero true correlation. The sample correlation must fall below a critical correlation value, which can be calculated from the $(1-\alpha)$ percentage point of the chi-square distribution:

$$
\rho_{\text {crit }}^{2}=\chi_{1}^{2}(1-\alpha) / n^{*}
$$

Since $\hat{q}$ is chi-square distributed with 1 degree of freedom, the mean (expected value $\langle\hat{q}\rangle$ ) is 1 . We use this relationship to estimate $n$ * by assuming a constant proportionality factor such that

$$
n^{*}=\hat{\nu} n
$$

Inserting (B4) into (B2) yields $\hat{\nu}$, which can be used to estimate $n^{*}$ required in (B3):

$$
\hat{\nu}=1 /\left\langle\hat{\rho}^{2} n\right\rangle
$$

In an application to the time-lagged correlation estimate, there are many estimates of $\left(\hat{\rho}^{2} n\right)$ (one at each lag), so we replace the expectation operator (angle brackets $\langle\quad$ ) with the average over $2 M$ lags (positive and negative lags):

$\hat{\nu}=2(M+1)\left(\sum_{m=M_{\min }}^{M_{\min }+M}\left\{\left[\hat{\boldsymbol{\rho}}_{(m)}^{2} n_{(m)}\right]+\left[\hat{\boldsymbol{\rho}}_{(-m)}^{2} n_{(-m)}\right]\right\}\right)^{-1}$, where both $\hat{\rho}_{(m)}^{2}$ and $n_{(m)}$ are functions of the lag index $(m)$. The limits, $M_{\min }$ and $\left(M_{\min }+M\right)$, are the range of lags over which the true correlation ought to be zero. Simulations have shown that this scheme is valid for $\hat{v}>0.1$.

For our purposes, we have chosen (somewhat arbitrarily) $M_{\min }=24$ months and $M=36$ months. Since we expect that $\hat{\nu} \leq 1, \hat{\nu}$ was set to 1 ( $n^{*}$ equals the number of observations) if $\hat{\nu}>1$.

Acknowledgments. We are deeply indebted to the staff at the FRF
who, over the last 16 years (and counting), have collected one of the
most outstanding nearshore morphology data sets in the world. In
particular, Mike Lefler has helped us understand the subtleties of the
FRF coordinate system and Cliff Baron has, patiently, helped us access
the data. The comments from Kathelijne Wijnberg, Irene van Enck-
evort, and two anonymous reviewers led to substantial improvements
of the original manuscript. The Office of Naval Research, Coastal
Dynamics Program (grant N00014-960237) and the Mellon Founda-
tion provided funding for this research. Additional funding was pro-
vided to N.G.P. by ONR through NICOP grant N00014-97-1-0793, PR
number 97PR184-00.

\section{References}

Bagnold, R. A., Mechanics of marine sedimentation, in The Sea, edited by M. N. Hill, pp. 507-528, Wiley-Interscience, New York, 1963.

Bailard, J. A., and D. L. Inman, An energetics bedload model for a plane sloping beach: Local transport, J. Geophys. Res., 86, 20352043, 1981.

Birkemeier, W. A., Time scales of nearshore profile change, in Proceedings of the 19th International Conference on Coastal Engineering, pp. 1507-1521, Am. Soc. of Civ. Eng., New York, 1985.

Birkemeier, W. A., and C. Mason, The CRAB: A unique nearshore surveying vehicle, J. Surv. Eng., 110, 1-7, 1984.

Bowen, A. J., Simple models of nearshore sedimentation: Beach profiles and longshore bars, in The Coastline of Canada, pp. 1-11, Geol. Surv. of Can., Ottawa, Ont., 1980.

Bowen, A. J., and D. A. Huntley, Waves, long waves and nearshore morphology, Mar. Geol., 60, 1-13, 1984.

Dally, W. R., Longshore bar formation-Surf beat or undertow?, in Coastal Sediments '87, pp. 71-86, Am. Soc. of Civ. Eng., New York, 1987.

Dean, R. G., Heuristic models of sand transport in the surf zone, in Conference on Engineering Dynamics in the Surf Zone, pp. 209-214, Am. Soc. of Civ. Eng., New York, 1973.

Gallagher, E. L., W. Boyd, S. Elgar, R. T. Guza, and B. Woodward, Performance of a sonar altimeter in the nearshore, Mar. Geol., 133, 241-248, 1996.

Holman, R. A., and A. J. Bowen, Bars, bumps and holes: Models for the generation of complex beach topography, J. Geophys. Res., 87, 457-468, 1982.

Jenkins, G. M., and D. G. Watts, Spectral Analysts and tts Applications, 525 pp., Holden-Day, San Francisco, Calif., 1969.

Komar, P. D., Beach Processes and Sedimentation, 429 pp., PrenticeHall, Englewood Cliffs, N. J., 1974.

Komar, P. D., and D. L. Inman, Longshore sand transport on beaches, J. Geophys. Res., 75, 5914-5927, 1970.

Lippmann, T. C., and R. A. Holman, The spatial and temporal variability of sand bar morphology, J. Geophys Res., 95, 11,575-11,590, 1990.

Lippmann, T. C., R. A. Holman, and K. K. Hathaway, Episodic, nonstationary behavior of a two sand bar system at Duck, NC, USA, $J$. Coastal Res., SI(15), 49-75, 1993.

Ooyama, K. V., Scale-controlled objective analysis, Mon. Weather Rev., 115, 2479-2506, 1987.

Raubenheimer, B., R. T. Guza, and S. Elgar, Wave transformation across the inner surf zone, J. Geophys. Res., 101, 25,589-25,597, 1996.

Ruessink, B. G., and A. Kroon, The behavior of a multiple bar system in the nearshore zone of Terschelling, the Netherlands, 1965-1993, Mar. Geol., 121, 187-197, 1994.

Sallenger, A. H., Jr., and R. A. Holman, Wave energy saturation on a 
natural beach of variable slope, J. Geophys. Res., 90, 11,939-11,944, 1985.

Sallenger, A. H., Jr., and P. A. Howd, Nearshore bars and the breakpoint hypothesis, Coastal Eng., 12, 301-313, 1989.

Sallenger, A. H., Jr., R. A. Holman, and W. A. Birkemeier, Storminduced response of a nearshore bar system, Mar. Geol., 64, 237-258, 1985.

Shepard, F. P., Submarine Geology, 338 pp., HarperCollins, New York, 1948.

Short, A. D., Three-dimensional beach stage model, J. Geol., 87, 553$571,1975$.

Sonu, C. J., Collective movement of sediment in the littoral environment, in Proceedings of the 11th Conference of Coastal Engineering, pp. 373-400, Am. Soc. of Civ. Eng., New York, 1969.

Sonu, C. J., Three-dimensional beach changes, J. Geol., 81, 42-64, 1973.

Thornton, E. B., and R. T. Guza, Energy saturation and phase speeds measured on a natural beach, J. Geophys. Res., 87, 9499-9508, 1982.

Thornton, E. B., R. T. Humiston, and W. Birkemeier, Bar/trough generation on a natural beach, J. Geophys. Res., 101, 12,097-12,110, 1996.

Wijnberg, K. M., and J. H. J. Terwindt, Extracting decadal morpho- logical behavior from high-resolution, long-term bathymetric surveys along the Holland coast using eigenfunction analysis, Mar. Geol., 126, 301-330, 1995.

Winant, C. D., D. L. Inman, and C. E. Nordstrom, Description of seasonal beach changes using empirical eigenfunctions, J. Geophys. Res., 80, 1979-1986, 1975.

Wright, L. D., and A. D. Short, Morphodynamic variability of surf zones and beaches: A synthesis, Mar. Geol., 56, 93-118, 1984.

Wright, L. D., A. D. Short, and M. O. Green, Short-term changes in the morphodynamic states of beaches and surf zones: An empirical predictive model, Mar. Geol., 62, 339-364, 1985.

W. A. Birkemeier, U.S. Army Corps of Engineers Field Research Facility, 1261 Duck Road, Kitty Hawk, NC 27942

M. H. Freilich and R. A. Holman, College of Oceanic and Atmospheric Sciences, Oregon State University, Corvallis, OR 97330.

N. G. Plant, Civil Technology and Management, University of Twente, 7500 AE Enschede, Netherlands (n.g.plant@sms.utwente.nl)

(Received July 9, 1998; revised February 26, 1999; accepted March 15, 1999.) 